\title{
Seeing Eye to Eye? \\ The presentation and understanding of interpretation at a New Zealand heritage site
}

\author{
By \\ Elise Caddigan
}

A dissertation submitted to Victoria University of Wellington in partial fulfillment of the requirements for the degree Master of Museum and Heritage Studies

Victoria University of Wellington

2014 


\section{Abstract}

Old St Paul's is an iconic New Zealand heritage site managed by Heritage New Zealand. ${ }^{1}$ It is a site that tells both national and local stories and draws a wide range of international and domestic visitors. Key recommendations made by the New Zealand Ministry of Tourism in their 2010 and 2015 strategies were that the country is no longer automatically perceived as 'authentic'² by international visitors, and that heritage in New Zealand should be striving to deliver engaging, educational and rich cultural and social experiences.

Using Old St. Paul's as a case study, this research asks if New Zealand heritage sites are providing exhibitions, interpretation and stories that successfully communicate the site management's presentation goals to visitors. This relationship is evaluated through the exhibitions and interpretation used by site management, and compared with visitor understanding and their experience of these.

This research uses interviews and visitor surveys to gauge the management/visitor relationship at Old St. Paul's. An in-depth interview with the site's manager is analysed and presented comparatively against the results gained from conducting visitor surveys. This research provides an investigation into contemporary heritage practice in New Zealand and offers a pilot study for future development in the heritage sector. Furthermore, it is suggested that heritage sites could adopt similar summative practices to those used in the museum sector in order to monitor visitor satisfaction and the perception of quality.

\footnotetext{
${ }^{1}$ Author's note: I would like to acknowledge that whilst conducting the research and writing of this dissertation Heritage New Zealand was known as the 'New Zealand Historic Places Trust'. The recent name change has been updated throughout the main dissertation as the change came in to effect before publication. I have kept direct interview quotations, website URLs and organisation documents as the 'New Zealand Historic Places Trust' as these are sources published prior to any name change.

${ }^{2}$ Author's note: As authenticity is a socially constructed notion which varies from individual to individual and group to group (see section 2.5 for discussion), I have placed the word in inverted commas throughout this dissertation to remind the reader of its constructedness.
} 


\section{Acknowledgements}

The completion of this dissertation is owed to many people whose support never wavered and who constantly reminded me that I can achieve anything that I set my mind to.

I must thank the manager and staff at Old St. Paul's, Wellington for allowing me to use their workplace as my case study heritage site. I appreciate the time spent showing me around, answering emails and being guinea pigs for my research! Thanks also goes to the many visitors to Old St. Paul's that contributed to this research by participating in the survey.

I would like to thank my supervisor, Lee Davidson, who has provided on-going advice and support throughout the past year. Thanks also to the other staff in the Museum and Heritage Studies programme for giving me a great experience throughout the past two years.

My husband and my family have been very patient and understanding during the course of the Masters degree, and it is to them that I owe the biggest thanks. Without their support, encouragement and interest I would not have been able to complete this dissertation, and I am grateful that I am surrounded by such wonderful people. 


\section{Table of Contents}

$\begin{array}{llr}1.0 & \text { Introduction } & 2\end{array}$

$\begin{array}{lll}2.0 & \text { Literature Review } & 5\end{array}$

2.1 Heritage Tourism

2.2 Heritage Tourism in New Zealand

2.3 Heritage Management

2.4 Site Interpretation

2.5 Visitor Experience

2.6 'Authenticity'

$2.7 \quad$ Visitor Studies

2.8 Conclusion

$\begin{array}{llr}3.0 & \text { Research Design } & 25\end{array}$

3.1 Background

3.2 Research Questions

3.3 Methodology

3.4 Case Study Selection

3.5 Methods

4.0 The Case Study Site: Old St. Paul's

4.1 History

4.2 Area's of Old St. Paul's

5.0 $\quad$ Findings $\quad 41$

5.1 Management's Goals and Objectives

5.2 Visitor Understanding

$\begin{array}{lll}\text { 6.0 } & \text { Discussion } & 58\end{array}$

6.1 Case Study Evaluation and Comparison

6.2 Secondary Questions

6.3 Objectives

7.0 Practical Management Recommendations for Old St. Paul's 66

$\begin{array}{llr}\text { 8.0 } & \text { Conclusion } & 68\end{array}$

$\begin{array}{lll}9.0 & \text { Appendices: } & 71\end{array}$ 
Appendix One: $\quad$ Visitor Survey for Old St. Paul's $\quad 71$

Appendix Two: $\quad$ Information Sheet for Visitor Survey at Old St. Paul's 74

Appendix Three: Information Sheet for the Manager of Old St. Paul's 75

$\begin{array}{lll}\mathbf{1 0 . 0} & \text { Bibliography } & 77\end{array}$ 


\section{List of Figures:}

Figure One: Old St. Paul's: Exterior sign 36

Figure Two: Old St. Paul's: Interior view of the nave 36

Figure Three: Old St. Paul's: View of the South transept window 36

Figure Four: Old St. Paul's: US Marines display 36

Figure Five: Old St. Paul's: Altar cloth/textiles display 37

Figure Six: Old St. Paul's: A South East view of the gothic panels and the pews 37

Figure Seven: Old St. Paul's: The 'Read this building' exhibition 38

Figure Eight: Old St. Paul's: Visitor host desk 38

Figure Nine: Origin of visitor $\quad 49$

Figure Ten: How visitors heard about Old St. Paul's $\quad 51$

Figure Eleven: Reason for visitation $\quad 51$

Figure Twelve: Area's of Old St. Paul's where the most time was spent 52

Figure Thirteen: Responses to why participants spent the most time in a particular area 52

Figure Fourteen: Identification and viewing of case site exhibition 54

Figure Fifteen: 'Stories' identified by visitors

Figure Sixteen: Highlight of visit $\quad 56$ 


\section{List of Tables:}

$\begin{array}{lr}\text { Table One: Visitor age groups } & 50\end{array}$

$\begin{array}{ll}\text { Table Two: Visitor gender } & 50\end{array}$

Table Three: Area's visitors spent the most time by reasons given 53

Table Four: Tours $\quad 54$

Table Five: Overall presentation of Old St. Paul's 56

Table Six: Comparison of exhibitions/themes at Old St. Paul's 59

Table Seven: Comparison of management and visitor stories at Old St. Paul's 60 


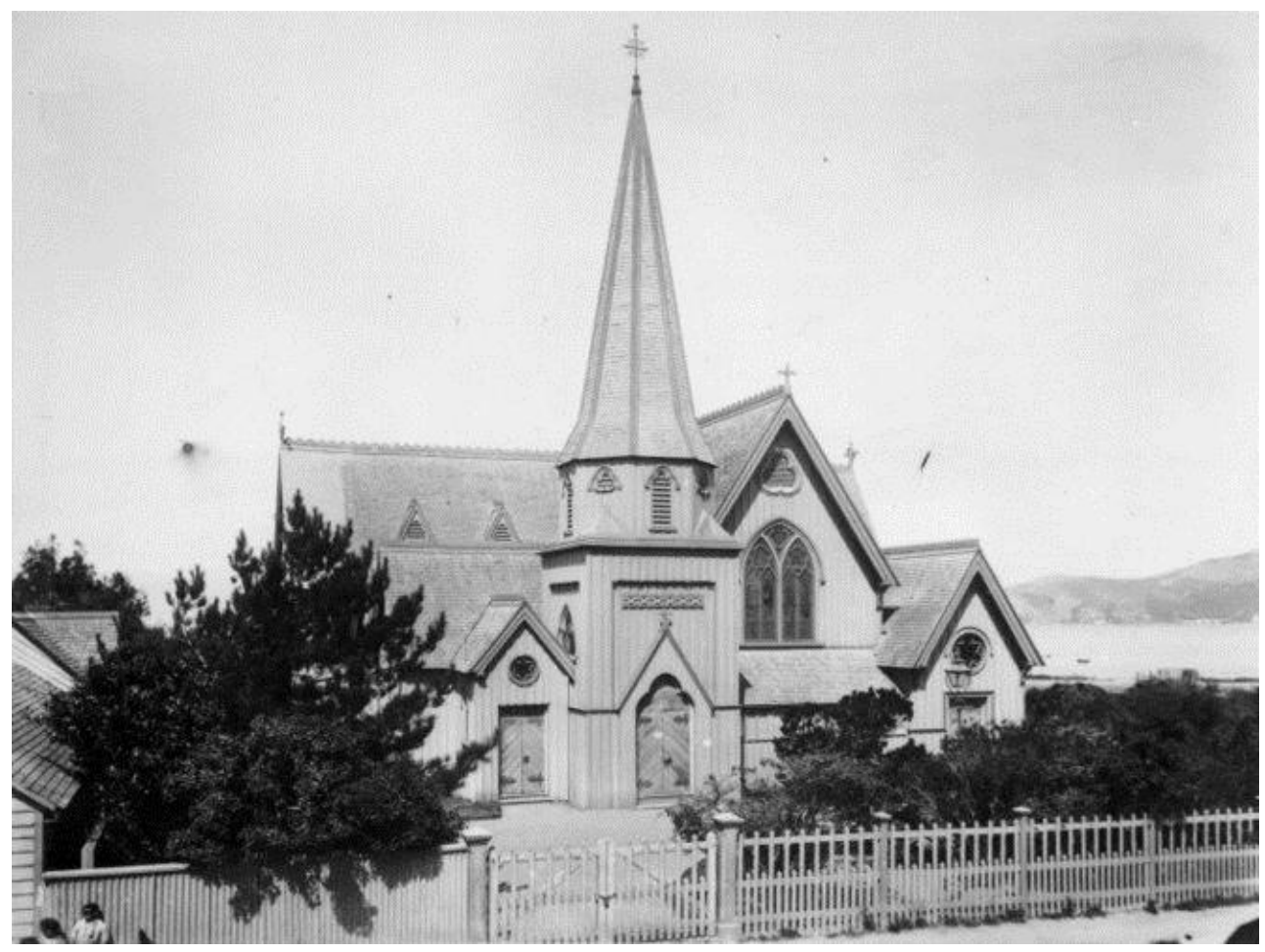

Old St. Paul's, c. 1882-1891.

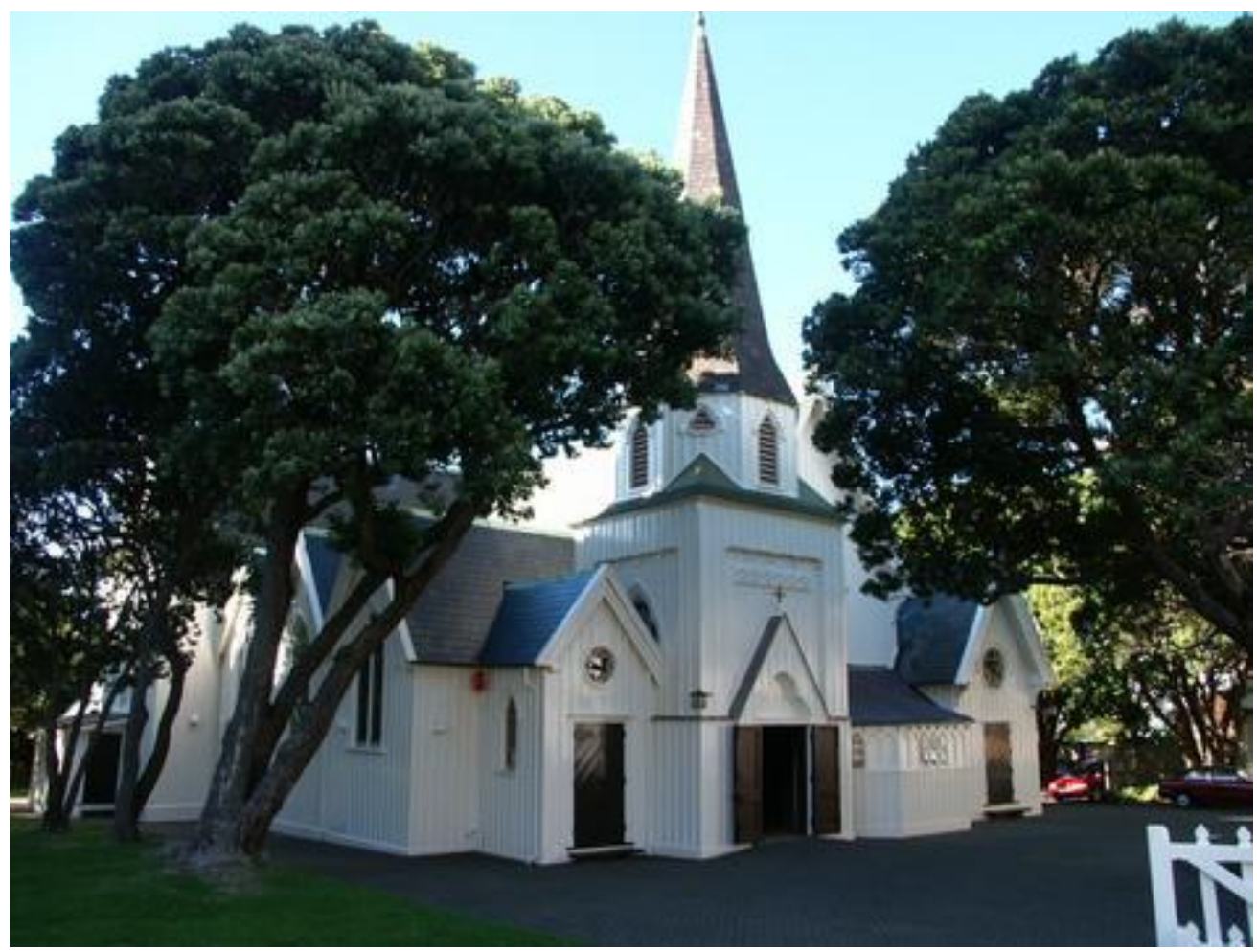

Old St. Pauls, 2012.4

\footnotetext{
3 “Williams, William, 1859-1949, St Paul's Anglican Church in Mulgrave Street, Thorndon, Wellington," last accessed 17 January 2014, http://natlib.govt.nz/records/22748744

4 “Old St. Paul's," last accessed 17 January 2014, kiwiscots.blogspot.com
} 


\subsection{INTRODUCTION}

This dissertation explores the relationship between how a heritage site is presented by its management and how visitors to the site understand this presentation. A significant way of presenting a heritage site is through the interpretation provided by the management and the evaluation of this relationship predominantly focuses upon this feature. Interpretation can include and is not limited to, exhibitions, multi-media displays, static displays and information panels. The presentation of the heritage site also includes how it is marketed, the interpretive tools used on-site and the overall impression. This is a piece of research that uses a number of mixed-method techniques to gather and analyse data in order to evaluate this relationship. The research encompasses a number of topical themes including heritage tourism, 'authenticity' and the construction of national identity.

As heritage sites compete for the public's leisure time, they are increasingly focussed upon business and financial management. It is a concern of the Ministry of Tourism, outlined in their 2010 strategy that New Zealand is no longer automatically perceived as 'authentic' by tourists. ${ }^{1}$ Heritage 'authenticity' has been defined by Seba as:

A way of promoting the true story of an area and is described as objective truth, a significant or distinctive asset, something real and tangible that visitors can experience and is supported by fact; this can be both activity-related and object-related. ${ }^{2}$

As heritage sites promote themselves as function venues and target advertising at new or different markets, the heritage value and integrity can be compromised. Additionally, the 2015 tourism strategy outlines that culture and heritage are two of three main draw cards of New Zealand which give a unique position as a tourist destination. The ' $100 \%$ Pure New Zealand' marketing campaign gives potential visitors high expectations of a clean, green and 'authentic' experience that need to be met. International visitor numbers are rising, ${ }^{3}$ contributing to the need to ensure more than domestic visitor satisfaction at heritage sites. An outcome outlined by the 2015 strategy states that heritage tourism sites need to provide visitors with a rich experience of

\footnotetext{
${ }^{1}$ New Zealand Ministry of Tourism, New Zealand Tourism Strategy 2010 (Ministry of Tourism, 2001 ), 60.

${ }^{2}$ Jaime A. Seba, Tourism and Hospitality: Issues and Developments (Point Pleasant, New Jersey: Apple Academic Press, Inc., 2012), 145.

3 "Seasonally adjusted visitor arrivals to New Zealand," last accessed 10 September 2014, http://www.med.govt.nz/sectors-industries/tourism/image-library/tourism-research-data/iva-yearly.png
} 
cultural and social values through quality interpretation and opportunities to learn and engage. ${ }^{4}$ Furthermore, the 2015 strategy emphasises the commitment tourist sites need to make to monitoring visitor satisfaction and perception of quality. A 'world-class' visitor experience includes a site being 'authentic' and providing high-quality interpretation of cultural and heritage stories. ${ }^{5}$ The strategy directly references the Heritage Destinations division of Heritage New Zealand as an integral part of creating national and local identity, giving quality visitor experience, and providing better interpretation and sharing stories. ${ }^{6}$

This has many implications for both domestic and international visitors. How New Zealand identities or stories are constructed at heritage sites contributes to a large portion of visitor education about the country, its history, people and actions. Considering that perceived 'authenticity' is a valuable asset to New Zealand, how well are heritage sites communicating themselves to their audiences?

After preliminary research into this question, I could not find any case study or model which evaluated a heritage site through the relationship between management goals and visitor understanding. As this is done in museums through models such as summative exhibition evaluations, I was surprised that a similar method was not utilised in heritage.

Museums align themselves with mission statements and strategic plans and objectives. For exhibitions they undertake summative evaluations to measure success and determine whether the exhibition met its predetermined targets. I believe that this method of internal appraisal should be transferred to the heritage sector. This evaluation would allow heritage sites to set goals and objectives directly related to presentation, interpretation and visitor understanding, and for these goals and objectives to be measured against visitors through surveys and interviews. These results could be used to gauge the success of what management teams want from the site interpretation and what is actually being presented to and understood by the visitor. If there is correlation then management can continue the current interpretation; if not, the exercise assesses where the site is lacking and changes can be made. If this evaluation model is consistently used,

\footnotetext{
${ }^{4}$ New Zealand Ministry of Tourism, New Zealand Tourism Strategy 2015 (Ministry of Tourism, 2007), 21.

${ }^{5}$ NZMT, Tourism Strategy 2015, 23.

${ }^{6}$ NZMT, Tourism Strategy 2015, 71.
} 
there would be less discrepancy, and a good alignment between management aims and what visitors receive. Heritage site management could be assured that what they wish to present to their visitors is what is being taken away. As interpretation and historical trends evolve, this system can help heritage sites to grow and to adapt alongside industry recommendations.

This research uses a New Zealand heritage site as a case study. Old St. Paul's, Wellington is operated by Heritage New Zealand (HNZ) and has the highest visitor numbers of any heritage site managed by the organisation. The two sides of the research are investigated, analysed, compared and discussed to evaluate how effective the presentation and interpretation is at the case study site. Although the scope of this dissertation limits the reach of the results, any findings will be useful and constructive for heritage in New Zealand and for the management of Old St. Paul's.

This dissertation begins with a literature review, which explores a number of key themes within the research, and is divided into two strands which represent each side of the research. Following this the research design outlines the research questions and objectives and the methods used to prepare and conduct the research. This is supplemented by a brief history of the case study site. The second half of the dissertation examines the findings of the research, analyses these findings and answers the research question in a discussion of the results. 


\subsection{LITERATURE REVIEW}

This literature review examines the two main topics central to my research. The first main topic is that of the heritage industry and current management practices. The second main topic is visitor studies and evaluation at heritage sites. The structure has been chosen to reflect the two sides of the research and for a detailed breakdown of the main themes within each part. Firstly, as an introduction to the review, the theme of heritage tourism is discussed in a broad sense with both international and national research and examples. Current definitions and critiques of heritage are offered alongside a discussion of the developing heritage sector in New Zealand. The first strand to this review is heritage management, which covers the overall management of heritage sites, how managers can present heritage, and mission statements for heritage. This section forms the first half of the research which will allow for the comparison of visitor experience with management aims. Heritage and heritage sites are then explored through a number of sub-sections including interpretation, visitor experience and 'authenticity'. This strand contributes to the second half of the research, which aims to gauge how visitors experience heritage and how they comprehend site presentation.

\subsection{Heritage Tourism}

Heritage tourism is a booming international industry. Increased mobility and travel have meant an increase in worldwide travel and resultantly, an increase in visitors to historic sites. Dallen J. Timothy defines heritage tourism as 'travellers seeing or experiencing built heritage, living culture or contemporary arts; its resources are tangible and intangible and found in both rural and urban settings. Visits are motivated by a desire to enhance one's own cultural self and to learn something new. ${ }^{1}$ However, many places of heritage which double as tourist attractions are prominently accused of presenting a distorted history. ${ }^{2}$ An issue is that these sites generate revenue, and therefore need to attract paying visitors. In some cases sites will display a particular identity which has been chosen by those in charge. Burnett claims that heritage must be seen to deliver the opportunity for all visitors to build, enhance or reorient their own (and

\footnotetext{
${ }^{1}$ Dallen J. Timothy, Cultural Heritage and Tourism (Bristol: Channel View Publications, 2011), 4.

${ }^{2}$ Kevin Walsh, The Representation of the Past: Museums and Heritage in the Post-Modern World (London and New York: Routledge, 1992), 109.
} 
others') sense of identity. ${ }^{3}$ It has been documented that only $21 \%$ of the New Zealand population are 'heritage minded' preferring holidays which involve visits to historic sites. ${ }^{4}$ The New Zealand government (and international governments) have reduced funding for heritage sites, and heritage has increasingly had to pay its own way through visitor fees; the development of such a philosophy has had substantial implications for the manner in which heritage is perceived and used, and how it is marketed and promoted to current and potential visitors. ${ }^{5}$ Rodney Harrison effectively summarises the current scepticism and criticism of heritage:

No matter how accurately history is represented by heritage, it can always be directed towards particular ends. The problem with official forms of heritage is not so much that it is 'bogus history' but that it is often directed towards establishing particular national narratives in reaction to the influence of globalisation on the one hand, and the local on the other. Heritage is primarily about establishing a set of social, religious and political norms that the nation-state requires to control its citizens, through an emphasis on the connection between its contemporary imposition of various state controls and the nation's past. $^{6}$

Here, Harrison is drawing upon the literature and ideas of academics such as Robert Hewison and Patrick Wright. Hewison, who first coined the phrase the 'heritage industry', suggested that the rise of heritage as a form of popular entertainment was a structure largely imposed from above to capture a middle-class nostalgia for the past as a golden age in the context of a climate of decline. ${ }^{7}$ David Lowenthal critiques the promotion of 'authenticity' in public heritage, listing numerous examples where costuming, theatre plays and movie scripts have been modified to make the past more accessible; he states that 'almost anything that makes the past seriously different is now apt to be axed as too hard for audiences to digest' 8 Such views are expressed by Kevin Walsh who is very critical of heritage tourism, including post-modern architecture, stating that the post-modern architect and the heritage conservation movement are together creating a built environment which represents a number of selected pasts in the present; such

\footnotetext{
${ }^{3}$ Kathryn A. Burnett, "Heritage, authenticity and history," in Quality Issues in Heritage Visitor Attractions, ed. Siobhan Drummond et al. (Oxford: Butterworth-Heinemann, 2001), 41.

${ }^{4}$ C. Michael Hall and Simon McArthur, Heritage Management in New Zealand and Australia: Visitor Management, Interpretation, and Marketing (Auckland: Oxford University Press, 1993), 4.

${ }^{5}$ Hall and McArthur, Heritage Management, 8.

${ }^{6}$ Rodney Harrison, "What is Heritage?" in Understanding the Politics of Heritage, ed. Rodney Harrison, (Manchester and New York: Manchester University Press, 2010), 18.

${ }^{7}$ Harrison, "What is Heritage?" 16.

${ }^{8}$ David Lowenthal, The Heritage Crusade and the Spoils of History (Cambridge: Cambridge University Press, 1998), 153.
} 
images represent an artificial ideal of a continuous historical identity. ${ }^{9}$ Walsh has examined a number of English heritage sites and concludes that first-person interpretation implies that the expert, or providers of heritage 'know' the past, which is unacceptable. ${ }^{10}$ Furthermore, he states that post-modern re-enactments de-contextualise history and in contrast to the argument that popularity equals acceptance, Walsh argues that popularity is hardly any guarantee of its own quality. ${ }^{11}$ Walsh is not convinced by heritage sites, calling them constructed 'time capsules' severed from history, islands of mediated image, sites of out-of-town heritage shopping. ${ }^{12}$ Walsh believes that the concentration on isolating historically unsubstantiated phenomena is an important characteristic of much heritage. Successful heritage centres are charged with the legitimisation of attractive myths into presentable and marketable heritage, removing any requirement to discuss 'real' history. ${ }^{13}$

\subsection{Heritage Tourism in New Zealand}

The heritage tourism industry is developing in New Zealand and functional aspects have been researched by Warren and Taylor. Through a compilation of surveys, it has been calculated that almost half of buildings used as a basis for heritage products had been public buildings such as banks, hotels and churches. ${ }^{14}$ Most of the site operators interviewed considered themselves as part of the heritage tourism sector because they were located in a heritage building.

Warren and Taylor identified three main reasons for visitor motivation and interest for visiting heritage sites: local and regional history; an interest in learning about New Zealanders and conserving heritage. ${ }^{15}$ While the first two motivations are to be expected, the third interest is problematic for heritage sites that are marketed as tourist destinations. Conflicts between heritage conservation and tourism development are common. There is a natural tension between tourism businesses, which are looking to gain profits and conservation activities. The increasing popularity of heritage tourism has meant that many sites of historical importance have become

\footnotetext{
${ }^{9}$ Walsh, The Representation of the Past, 86.

${ }^{10}$ Walsh, The Representation of the Past, 102.

${ }^{11}$ Walsh, The Representation of the Past, 103.

12 Ibid.

${ }^{13}$ Walsh, The Representation of the Past, 109.

${ }^{14}$ Julie A. N. Warren and C. Nicholas Taylor, Developing Heritage Tourism in New Zealand (Wellington: Centre for Research, Evaluation and Social Assessment Ltd, 2001), 13.

${ }^{15}$ Warren and Taylor, Developing Heritage Tourism, 42.
} 
threatened due to increased visitor numbers. ${ }^{16}$ Problems with visitation such as increased risk of fire, pilferage, graffiti, risks of car accidents, traffic congestion, parking, atmospheric pollution, impaired ambience, destruction of architectural and archaeological integrity and crowding have been noted in visitor studies. ${ }^{17}$ Tourism-specific threats incurred from mass tourism include graffiti, broken monuments and structures, wear and tear, litter and pollution. ${ }^{18}$ The development of heritage tourism is occurring at the same time as New Zealanders are increasingly concerned about the need to protect, conserve and restore heritage resources. ${ }^{19}$ Warren and Taylor are optimistic about the situation in New Zealand offering the advice that although there are negative impacts of tourism upon places with high heritage value, logical steps can be taken to ensure that tourism and heritage are allied. Strategic planning for the development and management of heritage resources needs to take tourism into account with respect to both positive and negative impacts. ${ }^{20}$ Additionally, the tourism industry needs to identify ways in which appropriate measures can contribute to heritage protection. Collier and Harraway state that the heritage sector has the potential to play an important part in New Zealand's overall tourism industry and in its approach to heritage awareness. ${ }^{21}$

The New Zealand Department of Conservation has identified that although heritage based tourism is a key growth area in the New Zealand economy, domestic visitors rate New Zealand poorly in terms of historic buildings. ${ }^{22}$ Their research suggests that improvements in the opportunities for and quality of historic sites, exhibitions, and buildings will have positive effects on improving visitor satisfaction. ${ }^{23}$

\subsection{Heritage Management (Site Management, Mission Statements and Presentation)}

Heritage management as defined by John Schofield is:

\footnotetext{
${ }^{16}$ Alan Collier and Sue Harraway, The New Zealand Tourism Industry (Auckland: Pearson New Zealand, 2005$), 9$.

${ }^{17}$ C. Michael Hall and Simon McArthur, Integrated Heritage Management: Principles and Practice (London: The Stationery Office, 1998), 1-3.

${ }_{18}$ Timothy, Cultural Heritage and Tourism, 214.

${ }^{19}$ Warren and Taylor, Developing Heritage Tourism, 91.

${ }^{20}$ Ibid.

${ }^{21}$ Collier and Harraway, The New Zealand Tourism Industry, 71.

${ }^{22}$ The Department of Conservation, Increasing public engagement with historic heritage (Wellington: The Department of Conservation, 2009), 24.

${ }^{23}$ Ibid.
} 
Putting in place systems to oversee and control the heritage, as well as providing opportunities for it to contribute to quality of life and sustainable living. These systems exist [...] at an international level through the International Council on Monuments and Sites (ICOMOS); nationally through legislation; and locally through planning guidance, amenity societies and by local communities. One can view this process from the top down, with influence and the principles of good practice cascading from the national to local authorities and communities, backed up by powers of enforcement. One can also view it from the bottom up, with the wishes, values and perceptions of local communities influencing budget-holders and decision-makers. ${ }^{24}$

Currently, much heritage management literature focuses on the collection of information to inform managers about financial and stakeholder goals. Heritage sites do participate in visitor research and the evaluation of their visitor management programmes, but as noted by Hall and McArthur, the data collected is used to identify logistical issues. Problems with visitation as detailed earlier have been collected through visitor studies. ${ }^{25}$ Strategic planning, heritage-visitor relationships and visitor management are all examined through a lens of policy and management criteria. Surveys focus on visitor satisfaction of the facilities, signage, parking and location. Eric Laws used Leeds Castle, Kent, England to explore the service blueprint in his article about managing visitor satisfaction. ${ }^{26}$ Using visitor diaries he analysed the appraisal of services on offer at the heritage site, including the approach to the castle, signing, interpretation and visitor flows through management set routes. Laws' article is exemplary of the literature of heritage site visitor management, distinguishing the features of policy and logistically-centred management.

The concept of stakeholders is becoming increasingly important in heritage management and planning, especially the community as owner and custodian of heritage. ${ }^{27}$ Stakeholder collaboration has been explored through a test model for preserving heritage and developing tourism at Luang Prabang in Laos. Implementation models were designed to form mutually beneficial alliances between historic and touristic ideals that were both economically profitable and socially acceptable with local inhabitants and other parties. ${ }^{28}$ Many heritage sites also have

\footnotetext{
${ }^{24}$ John Schofield, "Heritage Management, Theory and Practice," in The Heritage Reader, ed. Graham Fairclough et al. (London: Routledge, 2008), 21.

${ }^{25}$ Hall and McArthur, Integrated Heritage Management, 1-3.

${ }^{26}$ Eric Laws, "Conceptualizing visitor satisfaction management in heritage settings: an exploratory blueprinting analysis of Leeds Castle, Kent,” Tourism Management 19:6 (1998): 545.

${ }^{27}$ Christina Aas, Adele Ladkin and John Fletcher, "Stakeholder Collaboration and Heritage Management," Annals of Tourism Research 32:1 (2005): 33.

${ }^{28}$ Aas, Ladkin and Fletcher, "Stakeholder Collaboration," 29.
} 
associated groups such as the 'Friends of Old St. Paul's'. Individuals within these groups have a vested interest in the wellbeing of the site, and could be considered non-financial stakeholders. It is important that the community and stakeholders participate in the decision-making process and that processes are not highly centralised at a government level. ${ }^{29}$ Furthermore, survey research has shown that there is an implementation gap between the stated aspirations of a heritage site manager and the reality of what can been achieved; many managers of heritage sites lack the information, expertise and resources required to take appropriate actions to address rising issues. ${ }^{30}$ For many heritage sites, a tourism background is already established. For sites that are regulated and owned by the government, it can be difficult terrain to have high level decisions effectively passed through the ranks into action at the heritage site. Places such as Old St. Paul's find implementing nation-wide agendas difficult, as individual sites are not consulted in the construction of business and marketing models. Collaboration between high-level management and local stakeholders would reduce such issues and ensure a more effective and functional model to work within.

The role of the heritage manager is a profession that Peter Howard sees as evolving and encapsulates a variety of contexts, including museums, national parks, public buildings and government offices. ${ }^{31}$ Howard raised the idea of the 'professional trap', stating that a heritage site with 100,000 visitors a year will almost certainly require a team of professionals, including tourism managers to ensure success. This is placing high traffic heritage sites in a conundrum as to how far management needs to interfere with the site. A further observation is that because heritage managers concentrate their studies on public heritage, it becomes easy to forget that for most people the private heritage, their family and locality is much more meaningful. ${ }^{32}$ Resultantly, at all levels of heritage management there is now a major emphasis on participation with the public and especially with the local people. ${ }^{33}$ The reason Howard gives for this is because most heritage sites exist surrounded by local people who have a completely different and

\footnotetext{
${ }^{29}$ Aas, Ladkin and Fletcher, "Stakeholder Collaboration," 41.

${ }^{30}$ Susan Darlow, Stephen Essex and Mark Brayshay, "Sustainable management practices at visited heritage sites in Devon and Cornwall," Journal of Heritage Tourism 7:3 (2012): 226.

${ }^{31}$ Peter Howard, "The Rise of Heritage," Asian Anthropology 9 (2010): 2.

${ }^{32}$ Howard, "The Rise of Heritage," 15.

33 Ibid.
} 
much more functional attitude to the site. ${ }^{34}$ Howard points out that the National Trust in Britain now makes a considerable income from allowing their properties to appear in costume dramas, and makes a second income from the influx of visitors coming to see where, for example, Pride and Prejudice was filmed. ${ }^{35}$ Howard discusses challenges facing heritage management and suggests major trends within $21^{\text {st }}$ century heritage which allow for case-study comparisons.

Hall and McArthur promote the importance of heritage managers noting the broad mission of their agency or organisation, its purpose and the set of values it reflects. They believe that the values and ambitions of a heritage management agency can be set in a vision statement which provides the direction necessary to guide organisational and project goals, objectives, policies, strategies, implementation and evaluation. ${ }^{36}$ They write that the majority of management plans and programmes prepared by heritage agencies in New Zealand and Australia only set generalised long-term goals rather than obtainable, measurable objectives with a pre-determined time frame. ${ }^{37}$ However, these plans are directed at stakeholders, outlining financial performances rather than interpretive and visitor targets. Many New Zealand heritage sites either do not have, or do not publish their mission statements and objectives. Furthermore, existing plans do not include measurable goals in regard to visitor understanding of the management communication aims.

Practitioners of values-based management strive to identify and take these values into account in planning, physical treatments, and public interpretation efforts. Values-based management, if thoroughly and impartially executed, will result in more democratic and inclusive interpretations by accounting for the values of all stakeholders. ${ }^{38}$ Identification of a heritage site's total value in terms of both market (tourism) value and non-market (preservation) value will enable decision makers to enact more accurate and effective management decisions and policies. ${ }^{39}$ Using nonmarket value assessments, managers of historic sites can begin to minimise the conflicting

\footnotetext{
${ }^{34}$ Howard, "The Rise of Heritage," 7.

${ }^{35}$ Howard, "The Rise of Heritage," 8.

${ }^{36}$ Hall and McArthur, Integrated Heritage Management, 244.

${ }^{37}$ Hall and McArthur, Integrated Heritage Management, 245.

${ }^{38}$ John. H Jameson Jnr., "Presenting Archaeology to the Public," in The Heritage Reader, ed. Graham Fairclough, et al. (London: Routledge, 2008), 430.

39 Jameson, "Presenting Archaeology to the Public," 438.
} 
interests between market-based tourism interests and the non-market based preservation benefits that sites provide for society. ${ }^{40}$

\subsection{Site Interpretation}

Interpretation is a valuable management tool at heritage sites; it can manage crowds, conserve the past and educate the public. ${ }^{41}$ The interpretation of a site is a major influencing factor for visitors and is therefore one of the most important features of a heritage site. The following definition is taken from the International Council on Monuments and Sites (ICOMOS) Charter for the Interpretation and Presentation of Cultural Heritage Sites (2007 draft):

Interpretation: refers to the full range of potential activities intended to heighten public awareness and enhance understanding of cultural heritage sites. These can include professional and popular publications, public lectures, on-site installations, formal and informal educational programmes; community activities; and on-going research, training and evaluation of the interpretation process itself. ${ }^{42}$

The ICOMOS Charter for the Interpretation and Presentation of Cultural Heritage Sites lists seven general principles:

1. Access and Understanding: Interpretation and presentation programmes should facilitate broad physical intellectual access by the public to cultural heritage sites

2. Information Sources: Interpretation and presentation should be based on evidence gathered through acceptable scientific and scholarly methods as well as from living cultural traditions.

3. Context and Setting: The interpretation and presentation of cultural heritage sites should relate to their wider social, cultural, historical and natural contexts and settings.

4. Authenticity: The interpretation and presentation of cultural heritage sites must respect the basic tenets of authenticity in the spirit of the Nara Document (1994).

5. Sustainability: The interpretive plan for a cultural heritage site must be sensitive to its natural and cultural environment, with social, financial and environmental sustainability among its central goals.

6. Inclusiveness: The interpretation and presentation of cultural heritage sites must actively involve the participation of associated communities and other stake holders, recognising the validity of diverse perspectives and interests while encouraging tolerance and mutual respect.

\footnotetext{
40 Jameson, "Presenting Archaeology to the Public," 431.

${ }^{41}$ Timothy, Cultural Heritage and Tourism, 229.

${ }^{42}$ International Council on Monuments and Sites (ICOMOS), International Scientific Committee on Interpretation and Presentation, The ICOMOS Charter for the Interpretation and Presentation of Cultural Heritage Sites (Final Draft 2007), 4.
} 
7. Research, Evaluation and Training: Continuing research, training and evaluation are essential components of the interpretation of a cultural heritage site. ${ }^{43}$

Successful interpretation has been described as:

A catalyst in creating opportunities for the audience to form their own intellectual and emotional connections with meanings/significance inherent in the resource; is appropriate for the audience and provides a clear focus for their connection with the resource(s) by demonstrating the cohesive development of a relevant idea or ideas, rather than relying primarily on a recital of a chronological narrative or a series of related facts. $^{44}$

Although these definitions provide the ideal focus for heritage site interpretation, not all sites

follow such guidelines. Research shows that the experience of heritage is a personal engagement to stimulate us to reflect on who or what we are, and the interpretation of a site presents opportunities to reflect on social relations, value systems and tastes in both the past and contemporary times. ${ }^{45}$ Site interpretation takes many forms and Moscardo has found that interpretation in the form of 'stories' at heritage sites is a more effective technique than presenting lists of facts. ${ }^{46}$

Visitor preferences of the heritage experience should be clearly identified and the role of heritage management is to reveal whether visitors are interested in educational, emotional or non-serious experiences. ${ }^{47}$ Heritage managers need to leave behind their long-time perceptions of their role as educators of the public and adopt a 'responsible interpretation' which allows for the presentation of multicultural and conflicting narratives. ${ }^{48}$ Poria, Biran and Reichel state that the fact that tourists visit historic locations for different reasons should have implications for the marketing of sites; managers are advised to identify tourists based on their perceptions and provide them with different angles of interpretation. ${ }^{49}$

\footnotetext{
${ }^{43}$ ICOMOS, Charter for the Interpretation and Presentation, 7-14.

44 Jameson, "Presenting Archaeology to the Public," 433.

45 Burnett, "Heritage, authenticity and history," 41-2.

${ }^{46}$ Gianna Moscardo, "The shaping of the tourist experience: the importance of stories and themes," in The Tourism and Leisure Experience, ed. Michael Morgan et al. (Bristol: Channel View Publications, 2010), 48.

${ }^{47}$ Yaniv Poria, Avital Biran and Arie Reichal, "Different Jerusalem's for Different Tourists," Journal of Travel and Tourism Marketing 22 (2007): 135.

${ }^{48}$ Poria, Biran and Reichal, "Different Jerusalem's for Different Tourists," 136.

${ }^{49}$ Yaniv Poria, Arie Reichel and Avital Biran, "Heritage Site Management: Motivations and Expectations," Annals of Tourism Research 33:1 (2006): 174.
} 
Poria et al also identify that interpretation is considered to be a major element in the visitor experience, but that heritage settings often provide only one monolithic interpretation. ${ }^{50}$ Graham Black states that the interpretation of the heritage site should ensure that there are clear themes, reflecting the objectives of the site. ${ }^{51}$ Evidence suggests that sites of heritage are too focused on the educational aspects of interpretation and that no recognition has been given to the possibility that visitors may seek different experiences, other than learning. ${ }^{52}$ Poria et al highlight two different groups of tourists, the inquisitive ${ }^{53}$ and the identity builder. Inquisitive tourists are more interested in learning about other people's heritage and visiting sites not necessarily linked to their own personal heritage; identity builder tourists want to hear the history of the site told according to different historical sources. ${ }^{54}$

Jimson builds upon Tilden's well-known phrase of 'through interpretation, understanding; through understanding, appreciation; through appreciation, protection' and his six principles of interpretation to describe current best practice for developing interpretation and interpretive writing. ${ }^{55}$ Interpretation as described by Jimson, has a key function within the exhibition process, with the twin goals of ensuring that it is engaging and relevant for visitors and that the conceptual and scholarly aims of the project are realised. ${ }^{56}$ Furthermore, Jimson advises that the delivery devices or media that are used for the interpretation should employ a range of senses: verbal; visual; tactile and olfactory to ensure that the interpretation is as transparent as possible. ${ }^{57}$ This is so that visitors can evaluate the integrity of what is presented, thus making them selfconscious in the act of interpretation. ${ }^{58}$

Austin has conducted extensive interviews on site presentation and interpretation. Attention is concentrated upon prior expectations which can have significant bearing on the behaviour of the

\footnotetext{
${ }^{50}$ Poria, Biran and Reichal, "Different Jerusalem's for Different Tourists," 123.

${ }^{51}$ Graham Black, "Hows of concept design," in Quality Issues in Heritage Visitor Attractions, ed. Siobhan Drummond et al. (Oxford: Butterworth-Heinemann, 2001), 128.

${ }^{52}$ Poria, Biran and Reichal, "Different Jerusalem's for Different Tourists," 123.

${ }^{53}$ Italics were used by the article's authors and have been retained in the reference.

${ }^{54}$ Poria, Biran and Reichal, "Different Jerusalem's for Different Tourists," 133.

${ }^{55}$ Freeman Tildon, Interpreting our Heritage (Chapel Hill, NC: University of North Carolina Press, 2007 ), 38.

${ }^{56}$ Kerry Jimson, “Translating incomprehension into understanding: A case for interpretation," in Museum practice: The contemporary museum at work, ed. Conal McCarthy (Oxford and Malden MA: Wiley, forthcoming 2015).

57 Jimson, "Translating incomprehension into understanding,".

${ }^{58}$ Ibid.
} 
visitors. Such behaviour often involves a reaction to site presentation and interpretation, which subsequently influences site management's view of what the site should represent. ${ }^{59}$ This observation implies that there then needs to be a procedure in place to gauge what information visitors are taking away from the presented interpretation. Although in this case it is stated as something useful, such a procedure is not further explored or discussed. This furthers my argument that there is a basis for further research into this area.

Interpretation can be further broken down into different interpretation techniques. Studies into these include different modes of presentation, statistics on word counts and comprehension and the average length of time spent reading an interpretive sign. These techniques can inform heritage site managers as to the effectiveness of their interpretation and whether their chosen format is successful. Interpretive studies raise questions about whether interpreters need to choose between 'authenticity' and visitor engagement. This highlights the importance of having a mission statement and objectives for interpreters to follow. Without such guidelines interpretive strategies are unable to be refined or their success measured. Timothy advises that goals and objectives are important parts of interpretation planning which allow for a thorough analysis of existing interpretation; furthermore, analysing the effectiveness of interpretation is critical in maintaining an educational, informative and enjoyable heritage environment. ${ }^{60}$

\subsection{Visitor Experience}

The experience of a heritage site will determine whether a visitor will return, and positively or negatively recommend the site to others. This area of research broadly covers the visitor experience before, during and after the visit to the site. Poria, Biran and Reichel argue that studies perceiving heritage tourism as a leisure and recreation experience only may ignore aspects relevant to the understanding of the individual's behaviour in heritage spaces. ${ }^{61}$ Visitor preferences of the heritage experience should be clearly identified and the role of heritage management is to reveal whether visitors are interested in educational, emotional or non-serious

\footnotetext{
${ }^{59}$ Austin, "Managing Heritage Attractions," 448.

60 Timothy, Cultural Heritage and Tourism, 252.

${ }^{61}$ Poria, Biran and Reichal, "Different Jerusalem's for Different Tourists," 123.
} 
experiences. $^{62}$ Visitors can arrive at heritage sites with preconceived ideas and how sites are marketed has a big influence on this.

Very little research considers the relationship between the tourist and the visited space, a link that is regarded as important for better management of historic places. Included in a study by Poria, Reichel and Biran were questions about the visitor's motivations for visiting, the onsite interpretation expectations and overall experience. Based on the study findings by Poria et al, it is argued that the emotional link between the tourist and the site should be explored as relevant to the understanding and management of the site. ${ }^{63}$ Although it has been rarely highlighted in empirical studies, guides and the interpretations available have a considerable impact on structuring the visitor experience. ${ }^{64}$

Austin emphasises that in order to maintain visitor numbers, entertaining activities such as gift stores and souvenir photo opportunities at heritage sites are often utilised; trivialising the essence of the site. ${ }^{65}$ The physical environment of the site can affect the emotional state of the visitor, so entertainment coupled with an entrance fee can convey the feeling that a visitor's past is on sale for profit, which leaves a feeling of exploitation of self and of history. ${ }^{66}$ Again, in corroboration with similar literature, Austin recommends that rather than the portrayal of a confusing mixture of entertainment and education, marketing activities should enable the packaging of the site such that varying levels of opportunity for learning about the historical essence of the site remains the primary and dominant motivation for visitation. ${ }^{67}$

An exploratory study of public perceptions and expectations of New Zealand's historic and cultural heritage was undertaken by the Centre for Research, Evaluation and Social Assessment (CRESA) in 2000. ${ }^{68}$ Evaluation of this research by The Department of Conservation revealed a number of ways for engagement with historic heritage: historical, cultural, physical, aesthetic

\footnotetext{
${ }^{62}$ Poria, Biran and Reichal, “Different Jerusalem's for Different Tourists," 135.

${ }^{63}$ Poria, Reichel and Biran, "Heritage Site Management," 172.

${ }^{64}$ Poria, Reichel and Biran, "Heritage Site Management," 173.

${ }^{65}$ Austin, "Managing Heritage Attractions," 448.

${ }^{66}$ Austin, "Managing Heritage Attractions," 455.

${ }^{67}$ Ibid.

${ }^{68}$ DoC, Increasing public engagement, 21.
} 
and social. ${ }^{69}$ Although these types of engagement are seen as positive avenues for attracting visitors, a lack of these features or disagreement with a feature can quickly contribute negatively to a site. It is recommended that sites are marketed in a manner that is personally relevant and congruent to people's values and lifestyles. ${ }^{70}$

The results also suggest that heritage is an important part of the typical New Zealander's life and can assist in forming an individual's perception of local, regional and national identity. Howard emphasises the role that identity plays in the construction of heritage, listing nation-state building through to family life as significant elements that contribute to the understanding and experience at heritage sites. The visitor has the right to assume that everything in the presentation is accurate and reflects the latest research. It should be clear where reproductions or reconstructions are used and what the evidence for these is. ${ }^{71}$

\section{5 'Authenticity'}

Following the Charter of Venice (1964) 'authenticity' was acknowledged as the essential qualifying factor by which cultural heritage would be considered and valued, ${ }^{72}$ yet 'authenticity' at heritage sites is heavily contested and debated. For many scholars and practitioners 'authenticity' is objective and inherent in all buildings and objects; comparatively, 'constructivists" ${ }^{73}$ contend that 'authenticity' is subjective and variable, dependent upon the individual. Despite researchers not agreeing on a definition or set of criteria that can define what is 'authentic', several studies have tried to identify criteria by which the content of places and material artefacts can be judged as real or fake from the tourist's perspective. ${ }^{74}$ When considering 'authenticity' it is important to remember that cultural experts or 'heritage intellectuals' have different expectations of 'authenticity' to the tourism and heritage consumer. ${ }^{75}$ The meaning of an object, event or experience can be changed to suit different interpretations and furthermore, each individual will choose to take their own interpretation - their own personal

\footnotetext{
${ }^{69}$ DoC, Increasing public engagement, 33.

${ }^{70}$ DoC, Increasing public engagement, 41.

${ }^{71}$ Graham Black, "Whats, whys and whos of concept design," in Quality Issues in Heritage Visitor Attractions, ed. Siobhan Drummond et al. (Oxford: Butterworth-Heinemann, 2001), 114.

${ }^{72}$ Burnett, "Heritage, authenticity and history," 43.

73 Timothy, Cultural Heritage and Tourism, 107.

${ }^{74}$ Timothy, Cultural Heritage and Tourism, 109.

75 Burnett, "Heritage, authenticity and history," 46.
} 
sense of what is 'authentic', and this will differ from person to person. ${ }^{76}$ Any analysis model for 'authenticity' should reflect and represent multiple perspectives on what is 'authentic' or 'true' about a site or place and should provide a roadmap for practical solutions. The nature and qualifications of 'experts' on 'authenticity' should reflect the diversity of cultural affiliations and values attributed to the site, which, in turn, should be periodically reviewed and reassessed. ${ }^{77}$ Interpretation and presentation are central to the discussion on 'authenticity' and heritage interpretation provides the key to successful management - interpretation is the starting point and presentation the culmination. ${ }^{78}$

Jones believes that 'authenticity' is a key concept informing the preservation, curation, management and presentation of the historic environment. ${ }^{79}$ Jones suggests that current ideas about 'authenticity' are in part a reaction to increased social mobility, agricultural reform, industrialisation and urbanisation. ${ }^{80}$ The relationship between people, places and objects is central to this belief and therefore, the process of negotiating the 'authenticity' of material things can also be a means of establishing the 'authenticity' of self. Because the 'authenticity' of heritage objects is bound with past owners, past experiences, people and places to which the objects are connected, they are imbued with a unique and inalienable existence of the magic of being there. ${ }^{81}$ In contrast to popular definitions of 'authenticity', Jones proposes that this experience of 'authenticity' is not about date, original setting, design or material fabric, but about the ability to embody networks of relationships between people, places and objects.

The implications of this form of 'authenticity' reach into the management realm of heritage sites. As intangible qualities are seen as providing buildings and objects with a sense of 'authenticity', there is a need to incorporate these intangible and subjective qualities into both conservation practice and management plans. This has been recognised by the United Nations Educational,

\footnotetext{
${ }^{76}$ Ibid.

77 Jameson, "Presenting Archaeology to the Public," 437.

${ }^{78}$ Siobhan Drummond, "Critical success factors for the organisation," in Quality Issues in Heritage Visitor Attractions, ed. Siobhan Drummond et al. (Oxford: Butterworth-Heinemann, 2001), 18.

${ }^{79}$ Sian Jones, "Experiencing Authenticity at Heritage Sites: Some Implications for Heritage Management and Conservation," Conservation and Management of Archaeological Sites 11:2 (2009): 133.

${ }^{80}$ Jones, "Experiencing Authenticity at Heritage Sites," 136.

81 Jones, "Experiencing Authenticity at Heritage Sites," 137.
} 
Scientific and Cultural Organisation (UNESCO) as a problematic area to pursue. ${ }^{82}$ Jones has recommended that physical contact with objects/sites has increased the relationship between the person and 'authentic' experience. However, an implication of this is that in the management of many heritage objects and sites there is a tension between the physical preservation of sites/objects and the degree to which people are allowed to engage with them. ${ }^{83}$ Jones concludes by stating that there is increasing evidence of a self-reflexive and relativist approach towards 'authenticity', which can be seen through the interpretation and presentation of sites.

As previously eluded to, 'authenticity' from a visitor perspective can be affected by marketing. Popular promotional tools used by heritage sites are brochures, signage, printed media advertising and a web presence. ${ }^{84}$ Although these are effective tools, when the 'packaging' of heritage for consumption is over-marketed, the 'authenticity' of the site is affected. Such marketing can diminish the visitor's 'authentic' impression of the site, as the originality of the heritage is lost amongst the entertainment and comfort facilities. This is related to visitor experience, and is a concern for large heritage attractions that are included on a tour group itinerary.

Environmental sustainability is a growing and important feature for heritage sites, but can be difficult to implement in an 'authentic' fashion. Religious heritage places face problems related to the conflicted motivations of the various users of the building as religious buildings can be examples of architectural and cultural importance as well as performing as a place of worship. Measures to improve sustainability will not be adopted if they risk the integrity and diminish the 'authenticity' of the building. ${ }^{85}$ Installation of sustainable practices such as energy efficient equipment is not always unobtrusive and therefore will not always occur.

\subsection{Visitor Studies}

The importance of visitor studies at heritage sites has been explored by authors such as Beeho and Prentice who have published in the Tourism Management journal. They state that there is a

\footnotetext{
${ }^{82}$ Jones, "Experiencing Authenticity at Heritage Sites," 141.

${ }^{83}$ Jones, "Experiencing Authenticity at Heritage Sites," 143.

${ }^{84}$ Leanne Fullerton, Kathleen McGettigan and Simon Stephens, "Integrating management and marketing strategies at heritage sites," International Journal of Culture, Tourism and Hospitality Research 4: 2 (2010): 114.

${ }^{85}$ Darlow, Essex and Brayshay, "Sustainable management," 225.
} 
long tradition of visitor surveys at museums and heritage attractions; however, the majority of these studies do not focus on visitor experiences. ${ }^{86}$ Their article takes a heritage site as a case study and applies an evaluation technique through visitor surveys. It briefly outlines the site's objectives, and how these can be measured through the visitor responses. Although it is not the article's intention to match site objectives and visitor experiences, it provides an effective base for designing my own research. Similarly, Masberg and Silverman argue that 'in an industry so dependent upon the satisfaction of visitors, such a gap in knowledge and understanding seems unthinkable. Yet very little research into visitor experience at heritage sites has been adequately designed to explore the visitors' perspective rather than that of the professional or researcher. ${ }^{87}$ These ideas reinforce my argument that heritage site managers need to know what information visitors are taking away from their site. The majority of surveys undertaken by heritage sites focus on demographic information which is used for marketing and financial targets. Hall and McArthur argue that institutions need to evaluate the visitor experience through the examination of visitor characteristics and feedback. They consider that this form of evaluation, while perhaps being the most significant, is also the most neglected by heritage management agencies because it is typically regarded as unimportant. ${ }^{88}$

Creating an evaluative model for the management/visitor relationship is justified by the statement by Hall and McArthur that 'evaluation is critical as a means of obtaining performance feedback, as justification to continue or modify existing programmes, and as a basis for the implementation of new ones. ${ }^{89}$ This vein is also considered by Marion Blockley who expresses that 'visitor evaluation enables the interpreter to re-focus visitor activity through careful evaluation of the objectives of the interpretation and to undertake another cycle of construction. ${ }^{, 90}$ Graham Black furthers the argument, stating that heritage site managers should have clear aims and objectives for the presentation of the site; it is also necessary to undertake evaluations of these aims and objectives as unless initial aims and objectives are clearly defined,

\footnotetext{
${ }^{86}$ A. J. Beeho and R. C. Prentice, "Conceptualizing the experiences of heritage tourists: A case study of New Lanark World Heritage Village,” Tourism Management 18: 2 (1997): 75.

${ }^{87}$ Barbara A. Masberg and Lois H. Silverman, "Visitor Experiences at Heritage Sites: A Phenomenological Approach," Journal of Travel Research 34:20 (1996): 20.

${ }^{88}$ Hall and McArthur, Integrated Heritage Management, 16.

${ }^{89}$ Hall and McArthur, Integrated Heritage Management, 252.

${ }^{90}$ Marion Blockley, Heritage Interpretation (New York: Routledge, 2006), 94.
} 
it is impossible to have clarity in the message and the presentation of the message at the site. ${ }^{91}$ Black defines objectives as including defining a specific message or messages as the key themes for the presentation. ${ }^{92}$

Richard Harrison discusses the ever-changing presentation modes available to heritage sites and predicts that managers will have to respond to new forms of presentation to maintain visitation in periods of technological revolution. Harrison extends his discussion to evaluation, stating that 'in the absence of evaluation research it is difficult to know what key concepts and understandings visitors leave a heritage site with; it is suspected ${ }^{93}$ that many go away with collections of bits of information' but in such a disjointed pattern that articulation of the heritage story is inaccurate. ${ }^{94}$ The conclusions drawn from research associated with both heritage site interpretation and visitor experience can inform how the management present their sites. Current findings are integral to visitor studies and management practice because they are in contrast to popular procedures, which assume that individuals visiting a heritage site are interested in seeing representations of their heritage. The implications of these results affects heritage site management, as it is suggested that the current interpretation and packaging of heritage sites ignores the basic concept of modern marketing which is customer specific and understands consumer needs and wants. ${ }^{95}$

There are numerous visitor study methods available to enact when undertaking visitor research. Only the most common featured in the heritage literature so far will be discussed, as my method of choice will be explained in the methodology section. Hall and McArthur outline a number of principles that should be practised when collecting information from heritage visitors:

- Information should be collected from a range of reputable sources using a range of techniques, as a mean of minimising bias and maximising reliability

- Information should be collected from sample sizes that reflect the scale of the actual population or setting

\footnotetext{
${ }^{91}$ Black, "Whats, whys and whos," 105.

92 Black, "Whats, whys and whos," 106.

${ }^{93}$ Italicised words are the emphasis of the researcher in a direct quotation.

${ }^{94}$ Richard Harrison, Manual of Heritage Management (Oxford: Butterworth-Heinemann, 1994), 299.

95 Poria, Biran and Reichal, “Different Jerusalem’s for Different Tourists," 134.
} 
Information should be collected in a way that minimises disruption to the heritage and visitor experience

- Participants should always be advised who is collecting the information, what the purpose of the collection is and whether individual responses are to be publically displayed

- Participants and stakeholders should be offered the opportunity to access key results relevant to them, as a means of sharing benefits and establishing trust. ${ }^{96}$

Popular techniques for the collection of data include monitoring visitors, questionnaires, interviews, focus groups, needs assessments, counting and observations. An approach titled the 'Monitoring and Evaluation Model' highlights the importance of preparing a mission statement if one is not already utilised. ${ }^{97}$

Heritage sites, much like museums, are commonly answerable to stakeholders and funders for the assessment of projects, exhibitions and overall functionality. Visitor studies and summative evaluations are one way of gauging the success of a particular venture and for providing an informed snapshot of the organisation. Davidson summarises the history and development of visitor studies within the museum sector, and emphasises the importance of the methodological and theoretical sub-field. The sub-field has its origins in the late nineteenth century, yet very little systematic investigation of visitors occurred before the mid twentieth century when the study of visitors became more common. ${ }^{98}$ From the 1980 s through to the late 1990s new approaches to visitor studies resulted in the recognition that visitors had their own agendas and made meaning from experience according to their background, which led to new approaches of assessment and the professionalisation of visitor studies. ${ }^{99}$ Although aimed at visitor studies in the museum, Davidson's insights are transferable to the heritage field. Contemporary visitor studies are accepted as encompassing various forms of research and evaluation relating to both existing and potential visitors and wider communities. ${ }^{100}$ The use of evaluation to engage visitors in a dialogue about the effectiveness of exhibitions (and interpretive spaces) is a tool for developers, curators and interpreters allowing them to learn more about the needs and interests of

\footnotetext{
${ }^{96}$ Hall and McArthur, Integrated Heritage Management, 88.

${ }^{97}$ Hall and McArthur, Integrated Heritage Management, 95.

${ }^{98}$ Lee Davidson, "Visitor Studies: Towards a culture of reflective practice and critical museology for the visitorcentred museum," in Museum practice: Critical debates in contemporary museums ed. Conal McCarthy (WileyBlackwell, forthcoming 2015).

99 Davidson, "Visitor Studies,".

${ }^{100}$ Davidson, "Visitor Studies,".
} 
the visitors. ${ }^{101}$ Recent methodological innovations and their theoretical implications in the subfiled of visitor studies strengthens its intellectual foundations and gives the subject better standing within the field of critical museum studies. ${ }^{102}$ Furthermore, the advances made by visitor studies in the museum industry can be harnessed and applied to heritage sites, especially as the dialogue between theory and practice gives tangible results for managers of heritage sites to utilise.

\subsection{Conclusion}

This review has shown that heritage is a multi-faceted industry with numerous considerations for tourism, visitor experience and management. There is an on-going concern that heritage is becoming increasingly commoditised which is affecting a number of important heritage values. 'Authenticity' is a factor which is present in a number of issues around heritage including tourism, sustainability, marketing and importantly, experience. As heritage is vital in the construction of identity, the interpretation provided is an integral component of visitor understanding. The literature has revealed that many visitors to heritage sites arrive with preconceived ideas of what they expect to see. Visitor studies show that if these ideas are not met or are challenged, negative experiences can occur. Research implies that how management have marketed the site has a strong influence on these preconceptions. Heritage management has a large spectrum and sites vary in their level of applied management and efforts for presentation. Many heritage sites do not have mission statements or anything similar, and visitor evaluation is not common practice at heritage sites.

Heritage is a very important industry which has ties with tourism, the creation of national through to individual identity and can be the livelihood of many communities. How heritage is presented can be evaluated through the analysis of interpretation, perceived 'authenticity' and overall visitor experience. The literature review shows that each strand discussed is an important feature of heritage, but so far there are no published studies that evaluate visitor understanding against management goals for presentation and interpretation. Through the literature I have recognised that there is a gap in the management/visitor relationship, demonstrating that there

\footnotetext{
${ }^{101}$ Davidson, "Visitor Studies,".

102 Davidson, "Visitor Studies,".
} 
could be a significant lack of strategic planning at heritage sites. As shown in the review, heritage sites are seen as places that construct and present identities and are generally perceived by visitors to be 'authentic' representations of the past. Many heritage sites do not base their presentation and interpretation upon specific mission statements, objectives or guidelines, or evaluate their current presentation and interpretation, which the review has shown to be integral parts of the management of a site. The research that I have designed will evaluate whether this relationship gap is present at a New Zealand heritage site. As heritage tourism in New Zealand is a rapidly growing industry, it is important to understand how these visitors perceive our heritage and the stories that are being told. As the literature has highlighted these as important components to a heritage site, my research will focus upon both management and visitors; evaluating this relationship through management objectives and aims, the site's presentation and visitor understanding of exhibitions and interpretation. 


\subsection{RESEARCH DESIGN}

\subsection{Background}

This chapter outlines the research questions and objectives of this dissertation. The ideas for these have been informed by the literature review and a number of observations from the 2010 and current 2015 Ministry of Tourism strategies. As previously discussed, a concern in the 2010 tourism strategy was the perceived 'authenticity' of New Zealand. The importance of providing a cultural and social experience through quality interpretation has been highlighted. New Zealand heritages sites should be focussing upon visitor satisfaction, the perception of quality, 'authenticity' and engaging interpretation.

\subsection{Research Questions}

The aim of this research is to compare the presentation and interpretation goals and objectives of heritage site management with visitor understanding of the site. Evaluation of this relationship will determine whether or not the presentation goals outlined by site managers are being met. Such evaluation allows for the assessment of visitor comprehension through the interpretation prescribed by management and policy.

My primary question is:

Are New Zealand heritage sites providing exhibitions, interpretation and stories that successfully communicate the site management's presentation goals to visitors?

My secondary questions are specific to the case study heritage site that I am using for this research:

1. Does Old St. Paul's have presentation and interpretation guidelines?

2. How is their current interpretation evaluated?

3. What is the mission statement for Old St. Paul's?

4. What are the visitor learning outcomes prescribed by the management of Old St. Paul's?

5. What are the impressions of visitors to Old St. Paul's? 


\section{Objectives:}

Many heritage sites may not currently have mission statements or objectives. Through the analysis of the research I hope to encourage heritage sites to consider establishing mission statements and objectives, if they are not already in use. The monitoring and periodic evaluation of targets and goals can ensure that targets are being met. This activity also allows for the rectification of any arising issues. Re-development, re-interpretation and re-presentation can be options if any realignment is needed. I hope that this research will show that a consistent effort to monitor and evaluate goals is a worthwhile and important feature of managing a heritage site. I hope to show the significant role of heritage sites in the construction of identity and 'authenticity' in New Zealand.

\subsection{Methodology}

I have used a case study methodology with interviews and surveys. Initially, I thought that a number of case studies would provide a better indication of the results at heritage sites throughout New Zealand; but this would have resulted in a wide selection of shallow data, rather than an in-depth consideration of one example. Due to the scope of possible sites, interviews and surveys would not have been feasible for multiple case studies; therefore the majority of data would have been collected via electronic methods. This research method does not allow for spontaneous opinion and the analysis of multiple sites would be superficial. The scope of the dissertation (20,000 words) has also impacted upon this decision, as one case study has provided enough analysis to be discussed within the word limit. I have designed the research as a pilot investigation as the results will be primarily useful for only one heritage site. By constructing a pilot survey, the questions and analysis that I have used can be redesigned by other heritage sites to fit their specific needs. The success of the pilot will also be evaluated and recommendations considered for further development.

Case studies are often seen as prime examples of qualitative research. They adopt an interpretive approach to data, study 'things' within their context and consider subjective meanings that people bring to their situation. ${ }^{1}$ Case studies build up full pictures of a case, including context

\footnotetext{
${ }^{1}$ David de Vaus, Research Design in Social Research (London: SAGE Publications, 2001), 10.
} 
and are designed to study the whole, rather than parts. ${ }^{2}$ I chose a case study for my research as this method best reflects the investigation of my aims and objectives. This method is however, not without limitations. As this research considers a single heritage site, the results are limited in their transferable value to other New Zealand sites. Although the analysis may provide general evaluation of what is expected from a heritage site, the in-depth and specific answers will only be useful to the case study. As the case study is governed by the Heritage New Zealand, the managerial implications discussed will be relevant to a number of other heritage sites.

\subsection{Case Study Selection}

The proposed research was discussed with the national manager for Heritage Destinations, a department of HNZ that manages their heritage sites that can be publically visited. She suggested that the site of Old St. Paul's in Wellington would be suitable for the research as it is a popular tourist destination. This site was attractive for the research as the 2015 tourism strategy referenced the Heritage Destinations division of the HNZ. Furthermore, the HNZ website claims that 'HNZ's properties are authentic, in their original settings and form a network of places important to our national identity'. ${ }^{3}$ This statement covers a number of themes that my research aimed to investigate and therefore contributed to the decision to use a HNZ property. After an initial meeting with the manager of Old St. Paul's, the site showed potential as a basis for the research. The manager expressed interest in the research and offered Old St. Paul's as a heritage site and her full co-operation and support. Old St. Paul's has a lively history and the highest visitor numbers of any HNZ managed heritage site. The building offers a number of different stories, including two recently added exhibition areas. Old St. Paul's was purchased by the New Zealand Government in 1966 and renovated and re-opened to the public as a tourist destination in 1970. The majority of the heritage site has remained original, excepting the choir area which was re-modelled into staff offices; the vestry has become a gift store and the south transept was renovated into visitor bathrooms. Old St. Paul's is still consecrated; and hosts a number of weddings and christenings, whilst also being available as a venue to hire for functions.

\footnotetext{
${ }^{2}$ de Vaus, Research Design, 231.

3 “Home," last accessed 13 March 2014, http://www.historicplaces.org.nz/?sc_lang=en
} 


\subsection{Methods}

To explore the relationship between management presentation and visitor understanding, I have used both qualitative and quantitative methods, including conducting interviews and taking surveys. The formal interview with the manager of Old St. Paul's and the analysis of the transcript was a purely qualitative exercise. The visitor surveys used a mixed-methods approach as the questions asked gained data that was both qualitative and quantitative. The literature review highlighted a number of themes in the study of heritage sites, and the topics that were most integral to be discussed within the interview and surveys at Old St. Paul's were: interpretation, visitor management, policy management and visitor evaluation.

As this research evaluates visitor understanding and perceptions of the site against the management presentation and communication/interpretation goals, there were two comparable sources. The first was the data gained from analysing the management objectives, mission statements and policy towards the heritage site's presentation and interpretation. This data was gained from an interview with the site manager and the New Zealand Historic Places Trust (NZHPT) [HNZ] Statement of Intent 2013-16 (SoI) document. The second source of data was the results from analysis of the surveys undertaken with visitors to the heritage site. Before any research could be undertaken, ethical approval was needed for the project.

\section{Ethics:}

Ethical approval for the research was sought and received from the Victoria University Human Ethics Committee in September 2013. Ethical approval covered a range of aspects from management documents, consent and information forms and a draft survey. Separate information forms were required for the manager of the site and the participants of the surveys. Participants were considered to have given informed consent to the survey by reading the information sheet and agreeing to partake. A consent form was signed by the manager of the site before the recorded interview. This outlined the aims of the research, that I would not publish the manager's name and their right to edit and approve an interview transcript. It was agreed that participants had to be over the age of 15 as it was considered that by this age the individual could form their own opinions to effectively participate in the survey research. Documentation of all 
correspondence and the approval of all agreements in writing were essential to the flow of this project.

\section{Interview:}

An initial and informal interview was held with the manager in August 2013, which was used to assist in the construction of the visitor survey. This interview also established that Old St. Paul's does not have an individual set of objectives or statement of intent, so the goals of the site were drawn from a second and formal interview with the site manager. The formal interview with the manager and the first round of visitor surveys took place at the case study site on the $16^{\text {th }}$ December 2013. The interview with the manager of Old St. Paul's was approximately one hour and ten minutes. The topics that were covered included the management structure, presentation and interpretation guidelines, where the case site sits within a national model, marketing approaches and the manager's opinion on 'authenticity', visitor experience and identity at Old St. Paul's. As per the ethics considerations, the transcribed interview was sent to the manager for approval before the analysis took place. The interview structure combined two methods, that of standardised open ended and a guided approach. The basic questions were worded precisely in a pre-determined fashion, whilst topical questions allowed me flexibility in determining when it was appropriate to explore certain subjects in greater depth. ${ }^{4}$ The semi-structured, open-ended interview allowed for the general direction of questioning to be determined by myself, the interviewer, but left pre-set answers out in order to record the interviewees own opinion. Throughout the literature review, main themes emerged and these were the basis for the initial research into the management aims of Old St. Paul's. For the purposes of comparison, the visitor surveys were constructed around the same themes. As experienced by Marie Louise Stig Sørensen, it is best for the interviews to be structured around questions that are shaped by the expectation of how the interviewee will respond and what they can inform about. ${ }^{5}$ It is also important to have neutrality and rapport between the researcher and the interviewee. This ensures that the interviewee can say anything without engendering either favour or disfavour with regard to the content of the response. Establishing rapport conveys that the interviewee's

\footnotetext{
${ }^{4}$ Q Patton, Qualitative Evaluation and Research Methods (Newbury Park, California: Sage Publications, 1990), 287.

${ }^{5}$ Marie Louise Stig Sørensen, "Between the lines and in the margins: Interviewing people about attitudes to heritage and identity," in Heritage Studies: Methods and Approaches, ed. M. L. Stig Sørensen et al. (London; New York: Routledge, 2009), 169.
} 
knowledge, experiences, attitudes and feelings are important. ${ }^{6}$ These ideals are relevant to both formal interviews and surveys; rapport was gained with the manager of the case site through a full briefing of the research and its aims, and visits to the site pre-interview. The NZHPT [HNZ] SoI document supported the information gained from the interview.

\section{Surveys:}

A main research component for this study was conducting visitor surveys. This design was appropriate as I aimed to record how visitors understood the heritage site in their own terms. Survey research is the appropriate mode of inquiry for making inferences about a large group of people (visitors to Old St. Paul's) from data drawn on a relatively small number of individuals from that group (visitors who agree to be surveyed). The basic aim of survey research is to describe and explain the variability of certain beliefs or thoughts of a population. ${ }^{7}$ Other options such as observation and counting were not appropriate as I wanted to interact with the visitors and record their opinions and impressions. Researchers interview people to find out those things that cannot directly be observed such as feelings, thoughts and intentions; as the purpose of conducting surveys is to allow us to enter the other person's perspective. ${ }^{8}$ In order to be attractive to the visitors, the survey was less than ten minutes long. The construction of the survey relied upon an informal interview with the case site manager, as the survey questions were shaped by the general view of the management aims. In this interview the manager identified both marketing and interpretive tools that the site uses, acknowledged that there was no specific mission statement for the site and that there are no presentation guidelines. The survey questions focused upon how visitors comprehended the given interpretation and presentation of the case site, but also asked how they had heard about Old St. Paul's, how many times they had visited, the motivation for their visit and their thoughts on the gift store. The survey asked both open and closed ended questions, and was standardised so that visitors answered the same questions to increase the comparability of results. As stated by Hall and McArthur, it was important that the data collection did not affect visitor experience. Therefore, the surveys were completed at the exit of the heritage site. The literature review highlighted

\footnotetext{
${ }^{6}$ Patton, Qualitative Evaluation, 317.

${ }^{7}$ Catherine Marshall and Gretchen B. Rossman, Designing Qualitative Research (California: SAGE Publications, 1999), 130.

${ }^{8}$ Patton, Qualitative Evaluation, 278.
} 
some useful advice from authors who have conducted similar research. The methodological approach of Nathan K. Austin was based upon work in heritage tourism and was guided by the relatively short duration of visitors' tours at the site and the need for minimal disruption of the normal flow of visitor activity at the site. ${ }^{9}$ Similar tactics were used at Old St. Paul's for the same reasons given by Austin. Furthermore, Austin's survey included an analysis of the visitor comments register and interviews with the tour guides as well as with the visitors. These are also useful indicators and I explored the use of such data in my research. However, after my first round of collecting surveys, I decided against analysing the visitor register, as the comments made were the same as the answers given to my survey question asking for the visitor's overall impression of the site. I decided against interviewing the visitor hosts at Old St. Paul's as they were neither management nor visitors, and the information that could be gained from the exercise seemed minimal.

The survey participation audience was above the age of fifteen. There was no discrimination between international and domestic visitors, as I believed that the inclusion of a wide range of backgrounds would enhance the research. How heritage site managers present their sites affects all visitors, not only New Zealanders.

All participants were issued with a background information sheet and all of the surveys complied with the instructions given by the ethics committee. After the coding and analysis of the survey data, the paperwork was destroyed in line with ethics recommendations. Informed consent was gained from participants by ensuring that all potential interviewees read and fully understood the information sheet provided. In order to help ensure honesty from the participants, all individuals were given the opportunity to refuse and my independent status was emphasised.

Sample size depended upon the popularity of the heritage site and the number of visits I could undertake. I undertook visitor surveys at the case site on two separate occasions. A total sample size of 32 was collected; 14 surveys from the first visit on the $16^{\text {th }}$ December 2013 and 18 surveys from the second visit on the $13^{\text {th }}$ January 2014 . On the advice of the site manager, I waited until the summer months to begin my survey collection, as during these months the

\footnotetext{
${ }^{9}$ Austin, "Managing Heritage Attractions," 450.
} 
overall visitor numbers rise due to the increased occurrence of cruise ships in Wellington. On the two days that I was present, cruise ships were docked in Wellington and Old St. Paul's were expecting visitors from them. This increased the likelihood of international visitors participating in my surveys and gave the expectation that the site would be busy. When arranging which days to visit the site, communication with the site manager was essential to ensure that there were no conflicting scheduled events, including weddings, funerals and concerts. Due to other commitments, I could only be in Wellington early in the week. Although the cruise ships do not distinguish between weekdays and weekends, the manager advised that Old St. Paul's can receive higher visitor numbers over the weekend. The sample size could benefit from being larger; yet I felt that the sample was large enough for a pilot of the survey and to demonstrate its potential effectiveness as an evaluative tool. My method of approaching potential participants was to stand to one side of the church and ask each person who passed me if they would participate in the survey. At the conclusion of each survey I approached the next closest person. I completed 32 surveys from asking 33 visitors to participate. The one refusal I received was because the visitor did not speak English and therefore our communication was very limited. The information I gathered was analysed in order construct a number of key themes used for comparison against the management objectives. As the survey was structured and standardised, the majority of questions were pre-coded. The open-ended questions which asked for a visitor's opinion were coded after all of the surveys had been analysed and I could identify similarities and themes within the answers given. The qualitative and quantitative data gained from the surveys was compiled into tables, figures and comments.

Credibility for this research was ensured by following a number of recommendations, including: using research methods that are well established in general qualitative and quantitative investigation; adopting methods of data analysis that are derived from those that have been successfully utilised in previous comparable projects; developing a familiarity with the participating organisation before the collection of data, and establishing rapport with all individuals who participate, and the manager of the case study site. ${ }^{10}$ Standardised survey data collection for evaluation minimises issues of legitimacy and credibility by carefully collecting

\footnotetext{
${ }^{10}$ Andrew K. Shenton, "Strategies for ensuring trustworthiness in qualitative research projects," Education for Information 22 (2004): 64-72.
} 
the same information from everyone who is surveyed. ${ }^{11}$ Further credibility was ensured by allowing all participants ample time to consider the questions and their answers, as well as conducting the surveys where the respondent was comfortable giving open responses.

The final stage of the research was the comparison of each part of the relationship. This determined whether visitor understanding met management objectives.

\footnotetext{
${ }^{11}$ Patton, Qualitative Evaluation, 286.
} 


\subsection{THE CASE STUDY SITE: OLD ST. PAUL'S}

This chapter gives a brief history and introduction to the heritage case site that this research uses. A description of the exhibitions, interpretation and displays at Old St. Paul's is given, supplemented by photographs I have taken in December 2013 and January 2014. These document exterior signage, areas of the interior of the site, and places of exhibition and interpretation. I discuss how I have defined these areas in relation to the visitor survey and findings.

\subsection{History}

The foundation stone for Old St. Paul's was laid in August 1865 by the Governor of New Zealand, Sir George Grey and the new cathedral was consecrated by Bishop Abraham on the $6^{\text {th }}$ June 1866. The architect of the cathedral church was the Reverend Frederick Thatcher (18141890), who was also vicar of the parish from 1861 to $1864 .{ }^{1}$ One of Bishop Selwyn's most able architects, Thatcher's works were scattered across the North Island, in Auckland, the Waikato, Taranaki and Wellington. ${ }^{2}$ The style of architecture he used for Old St. Paul's was Gothic Revival and he adapted the style for the church to be built entirely from wood. The church was aligned for liturgical reasons on an east-west axis, however this was climatically disadvantageous; the prevailing winds would strike the long unbuttressed sides of the church with such force that in the winter of 1867 the parish determined to strengthen it with transepts. ${ }^{3}$ In the decade after 1883 several additions were made to increase the comfort of the church, including a porch between the clergy vestry and south aisle; an extension of the baptistery; the removal of the iron roof and its replacement with slates, and the addition of a robing room. ${ }^{4}$ As early as 1895 remarks were made that Wellington needed a proper cathedral and in the period from 1909 to 1938 many donations and ideas were flowing around the reconstruction of Old St. Paul's. The 'Lady Chapel' scheme was decided upon, which would replace the Thatcher exterior of Gothic Revival design with new concrete walls in the Perpendicular style. ${ }^{5}$ Much of the interior would also be changed with only the east end of the old church remaining. However, the

\footnotetext{
${ }^{1}$ Dallas Moore, Old St. Paul's: The First Hundred Years (Wellington: Government Printer, 1970), 8.

${ }^{2}$ Ibid.

${ }^{3}$ Ibid.

${ }_{5}^{4}$ Moore, Old St. Paul's, 10-11.

${ }^{5}$ Moore, Old St. Paul's, 14.
} 
war prevented an early start being made on the cathedral and post-war suburban expansion absorbed the diocese's energies for several years. ${ }^{6}$

Old St Paul's became the scene of one of New Zealand's greatest heritage battles. As the diocese tried to dismiss the church that had served them for almost 100 years, strong protest from a small group captured significant public support. ${ }^{7}$ Unwilling to see the church demolished or remodelled, for twelve years the Vestry of St. Paul's parish, the Cathedral Committee, the Historic Places Trust, the Society for the Preservation of Old St. Paul's and its successor the Friends of Old St. Paul's pursued a debate on the fate of the building. ${ }^{8}$ The campaign for full preservation was won in May 1961 when the 'Lady Chapel' scheme was abandoned. On the $10^{\text {th }}$ May 1964 the church was closed, but not deconsecrated. The diocese offered the church to the Government and this offer was accepted on the $21^{\text {st }}$ November 1966. Restoration started in 1967 and the church was opened to the public again in 1970. Old St. Paul's stands as a memorial to all who have worshipped in it and provides a unique setting for music; it is a building that boasts architectural and historical associations which have created a site that is cherished by locals and is nationally recognised. ${ }^{9}$

In the opinion of The Most Reverend A.H. Johnston, Archbishop and Primate of New Zealand, the preservation of Old St. Paul's has enriched the cultural heritage of New Zealand, and made possible a visible link with the spiritual history of the Church in Wellington; Old St. Paul's today is a reminder of values that helped to lay the foundation of our national life. ${ }^{10}$ The HNZ website describes Old St. Paul's as telling of New Zealand's journey from colony to independent nation through social history. ${ }^{11}$ Contemporary Old St. Paul's is a favoured venue for a variety of events including weddings, concerts and cultural occasions. The case study site draws 90,000 visitors annually; 30,000 from venue hire and events, and 60,000 through both domestic and international tourists.

\footnotetext{
${ }^{6}$ Moore, Old St. Paul's, 15.

7 "Places to visit," accessed 10 April 2013, http://www.historicplaces.org.nz/placestovisit/lowernorthisland/oldstpauls/history.aspx?sc_lang=en

${ }^{8}$ Moore, Old St. Paul's, 15.

${ }^{9}$ Ibid.

${ }^{10}$ Deric N. Bircham, Old St. Paul's: An Illustrated Essay (Wellington: A.H \& W. Reed Ltd, 1981$), 1$.

11 "Places to visit."
} 

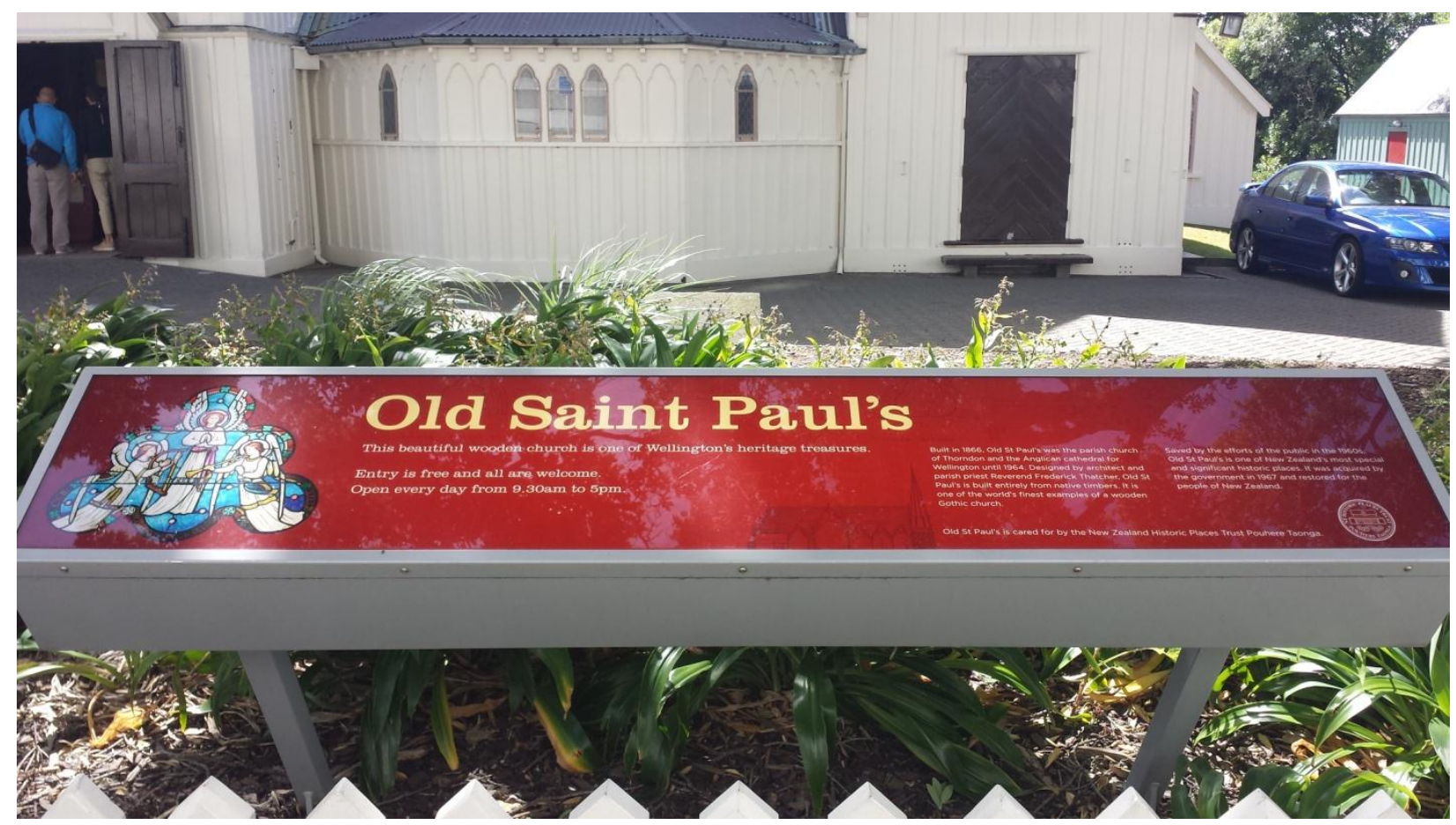

Figure One: This sign faces the foot path and is at the entry to Old St. Paul's.

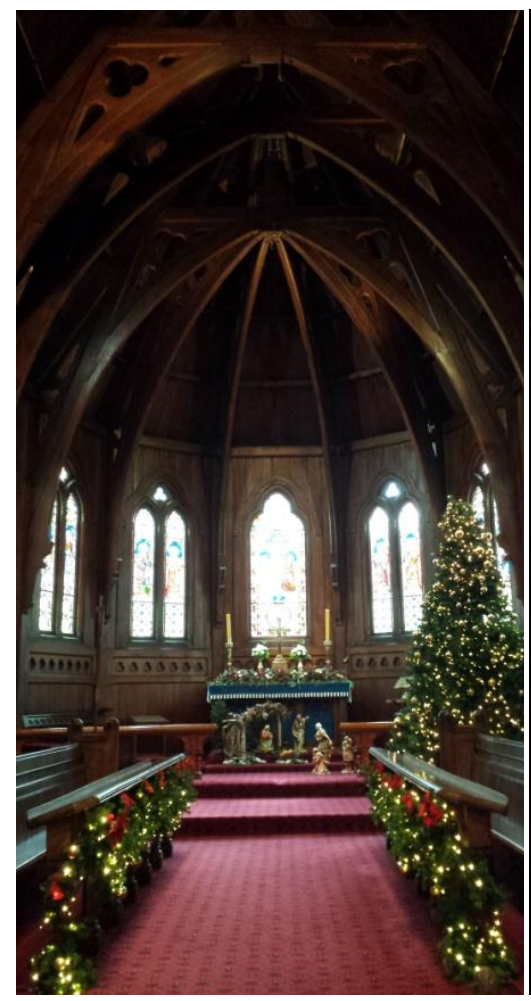

Figure Two: The nave of Old St. Pauls.

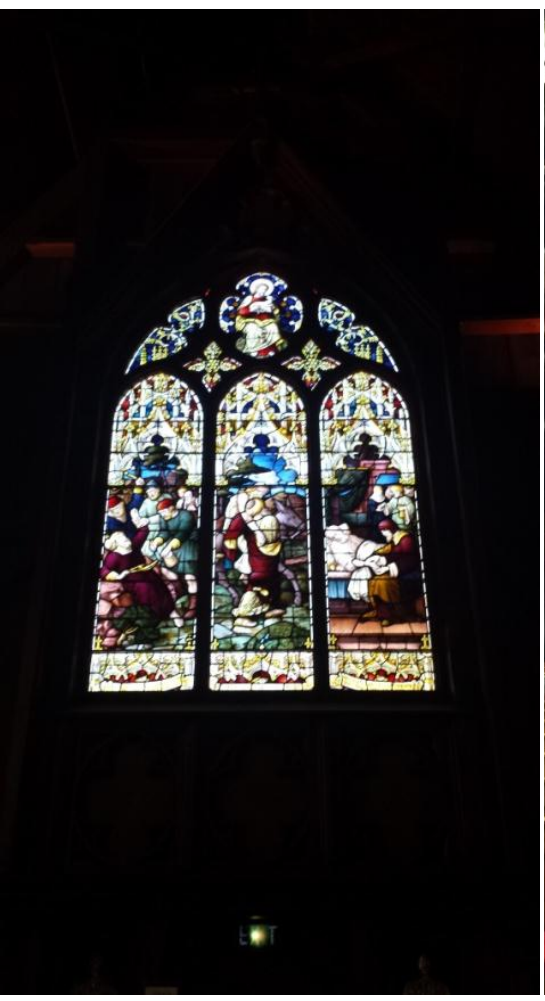

Figure Three: The south transept window.

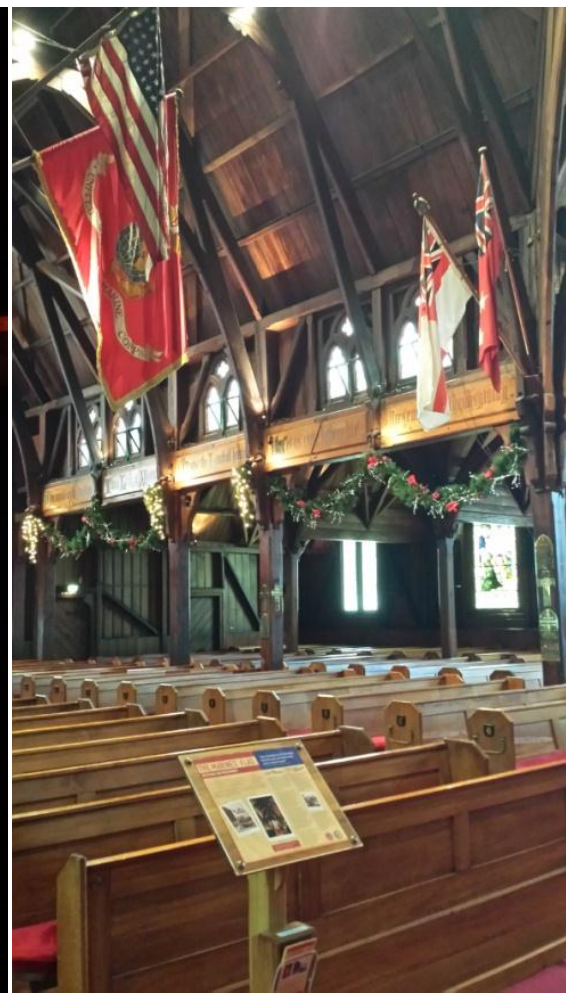

Figure Four: The US Marines flag display. 


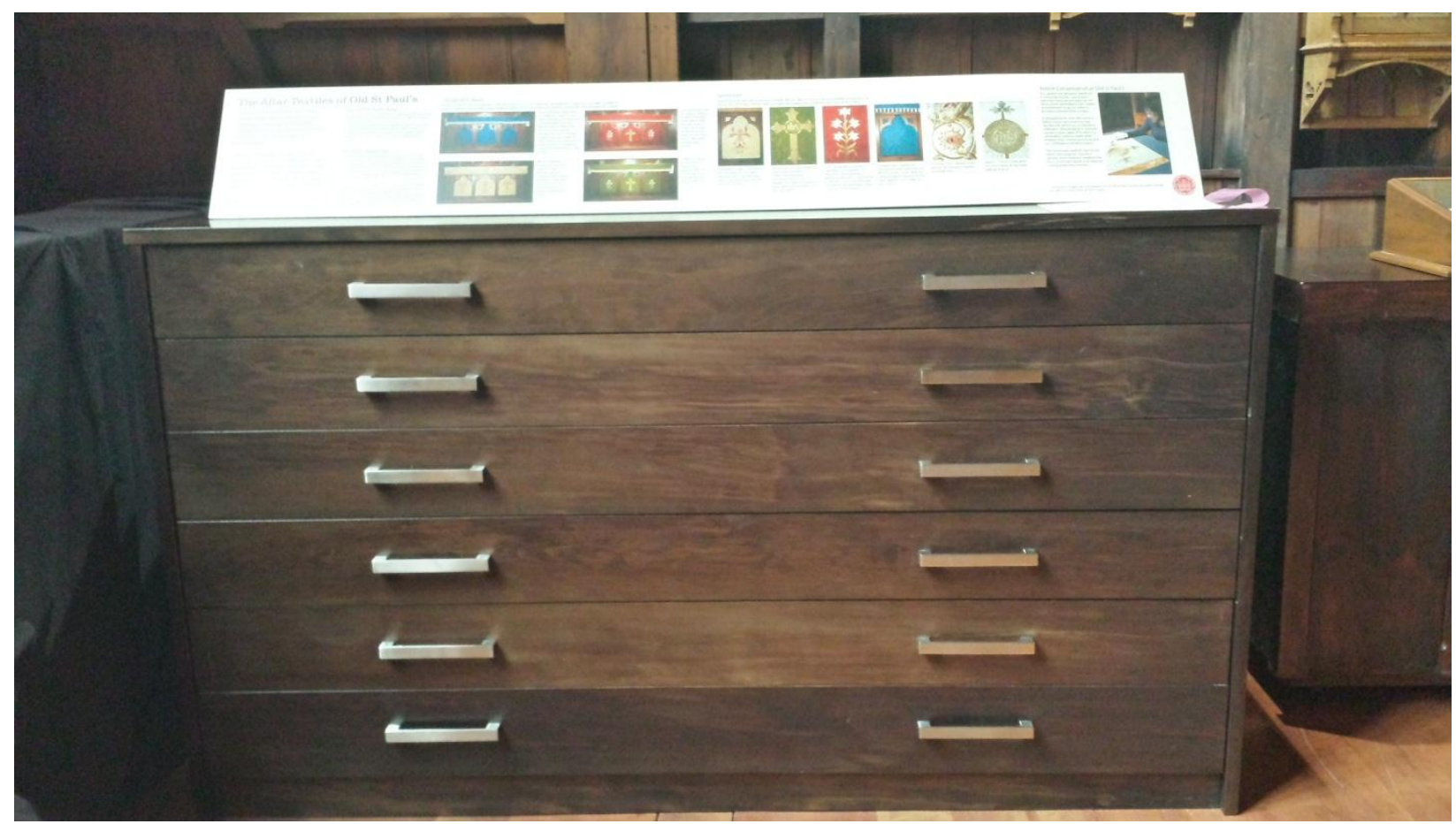

Figure Five: The altar cloth display drawers.

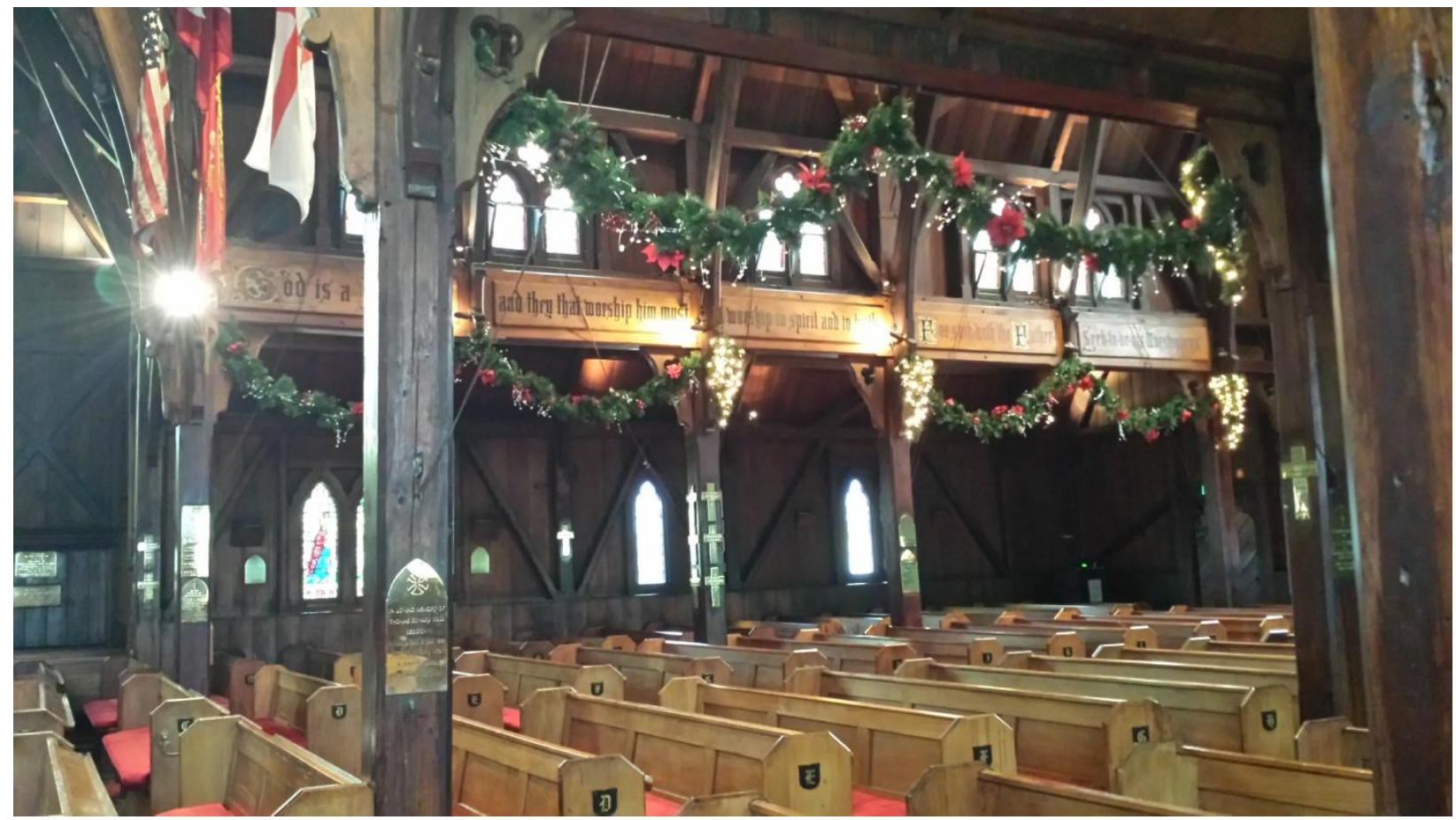

Figure Six: A south-east view of the gothic panels and the pews. 


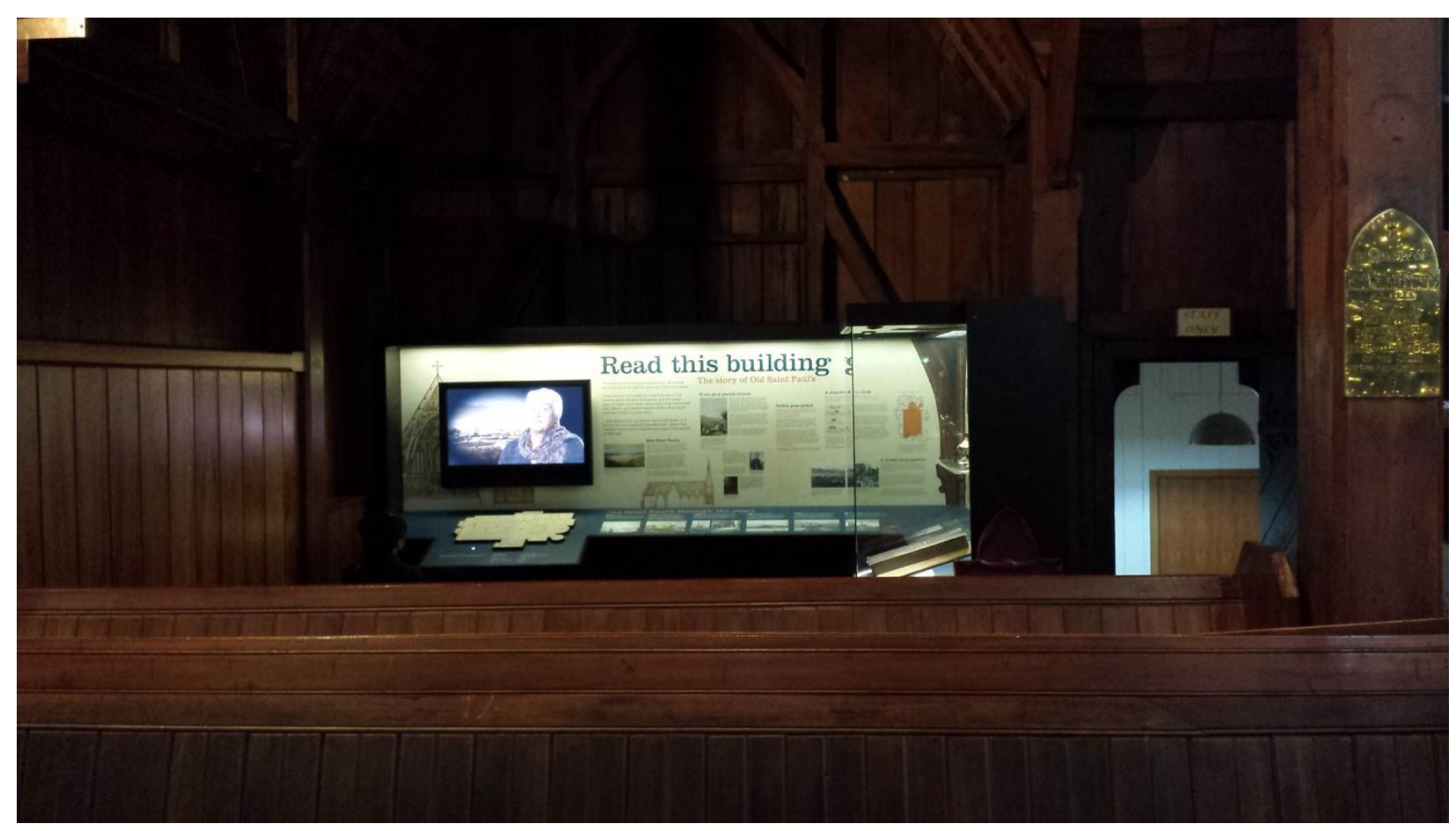

Figure Seven: The 'Read this building' exhibition. This is located to the left of the nave.

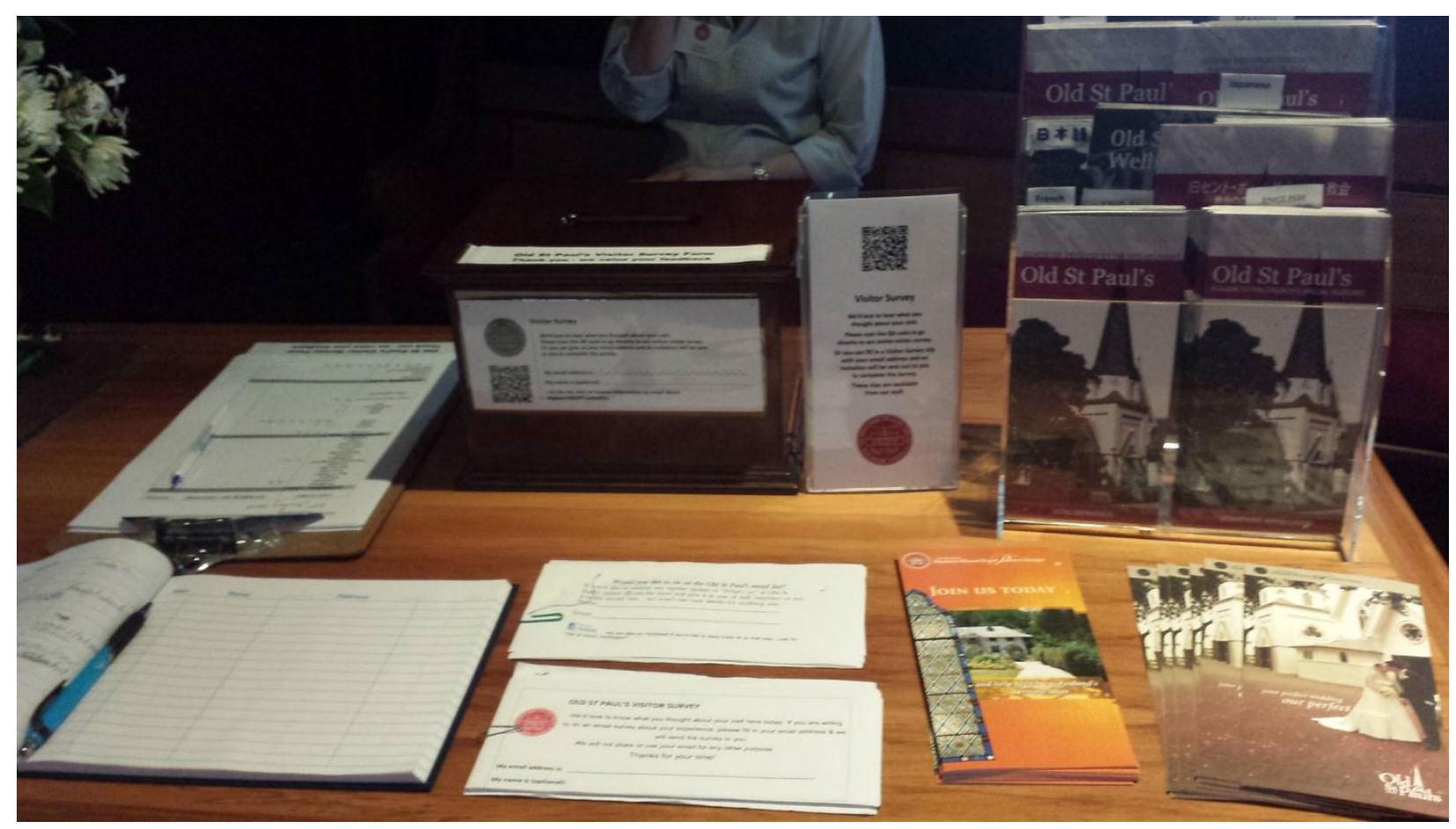

Figure Eight: Examples of tour guide brochures and information booklets alongside the visitor book. 


\subsection{Area's of Old St. Paul's}

For the purpose of this research I have defined any area of Old St. Paul's that provides interpretation, an information panel, a story or a display as an exhibition. This definition was used in the visitor surveys in order to encompass any of the above areas that the visitor could consider having seen.

Figure Two shows the nave of Old St. Paul's, which some visitors described as the 'altar' in their survey responses. There is no interpretation in this area and therefore I have not considered it as an area of exhibition.

Figure Three shows an example of the stained-glass windows that are at Old St. Paul's. An interpretive self-guide booklet to the windows is available for visitors to use which gives a tour of the windows alongside each window's description, history and local connection. Figure Four is a photograph of the US Marines display. The display consists of four flags, accompanied by an information panel and pamphlets. Figure Five shows the altar cloth or textiles display drawers. Six drawers can be pulled out to reveal different cloths used by Old St. Paul's. An information panel is placed on top of the drawers, explaining the colours and which religious season they are used in.

Figure Six shows an area of pews at Old St. Paul's and memorial plaques can be seen on the beams. These plaques remember parishioners of Old St. Paul's, and as with some of the stainedglass many were erected in memory of Thorndon locals. Figure Six also illustrates some of the gothic timber detailing and panelling. Figure Seven is a photograph of the 'Read this building' exhibition area. The HNZ website offers this description of the exhibition:

This multi-media exhibition tells the wonderful and sometimes quirky stories of the church, its site and people on a journey from colonial times until the present through 12 short videos, artefacts and informative panels. ${ }^{12}$

The final photograph, Figure Eight, is an image of the front desk at Old St. Paul's. This is where visitors can take an information brochure, find the stained-glass window guide, fill in the visitor

\footnotetext{
12 "Read this building," last accessed 10 April 2013, http://www.historicplaces.org.nz/exhibitionsandtours/readbuilding.aspx
} 
book and leave their details for the visitor survey. An Old St. Paul's host is usually around this area, ready to provide assistance to visitors. 


\subsection{FINDINGS}

This chapter looks at the information gathered through the formal interview and visitor surveys. The first section is a summary of findings from the interview undertaken with the manager of Old St. Paul's, supplemented with relevant extracts from the NZHPT [HNZ] SoI. These two data sources provide the basis for addressing the first part of the research, to determine the management's aims and objectives for the presentation and interpretation at the case study site. The second section of this chapter discusses the visitor surveys completed at Old St. Paul's. The surveys have been coded and presented as graphs and tables to address the second part of the research, to see how visitors understand the presentation and interpretation at the case study site.

\subsection{Management's Goals and Objectives}

The first part of this dissertation's enquiry asks what the management's goals and objectives are for the presentation and interpretation of the heritage case site. This section includes a discussion of interpretation and presentation goals, 'authenticity', marketing strategies and the overall management of Old St. Paul's. Analysis of this data provides the first half of the comparison that this dissertation is examining.

As Old St. Paul's is part of HNZ, the manager drew upon the national guidelines to discuss the mission statement and objectives of the site. The SoI defines Old St. Paul's as a well-known and visited property which forms part of the developing tourism network. ${ }^{1}$ The HNZ department that the site belongs to is Heritage Destinations. This means that Old St. Paul's is a property that can be visited, and therefore the mission statement of the NZHPT [HNZ] SoI applies to the site. In particular, the 'Heritage Appreciation' section of the SoI relates to the site. "Intermediate Outcome Three: Heritage Engagement: New Zealanders engage with those places that contribute to New Zealand's culture and heritage"2 was highlighted by the manager and discussed in detail:

Before we can actually appreciate heritage we need to identify heritage, what is an historic place and then make sure that it survives. [...] so the identification and survival of our heritage places are prerequisites for their appreciation by both present and future generations. [...] this is achieved by both experiencing heritage places and having access to the stories that explain their significance. So telling the story is a bit of our mission

\footnotetext{
${ }^{1}$ New Zealand Historic Places Trust, Statement of Intent 2013-16, 17.

${ }^{2}$ NZHPT, Statement of Intent, 21.
} 
really. ${ }^{3}$ Telling the stories of our heritage places helps us to understand our collective past and develops an appreciation of the value of these places and leads in turn to their conservation for the benefit of both past, present and future generations. Properties cared for by the NZHPT provide perhaps the most important and publically accessible means of experiencing New Zealand's most significant heritage places.

Therefore an objective of Old St. Paul's is to provide an experience that allows for its story to be told. Telling this story helps visitors to understand its past and to develop an appreciation of this past, which leads to the continual conservation of the heritage site. Old St. Paul's has been identified as providing a national narrative that needs to be appreciated and conserved for everybody. The SoI directly addresses the responsibility of Heritage Destinations properties by stating that such sites should reflect the increased focus on encouraging New Zealanders and international tourists to visit these places. In showcasing significant properties, HNZ engages visitors in an experience that increases their understanding of New Zealand's past, New Zealand's cultural identity and, for New Zealanders, their place within it. ${ }^{4}$ This is a significant objective of Old St. Paul's in addition to the objectives and missions stated by the manager.

The overall management structure and role of the property manager situates Old St. Paul's within HNZ and shows the channels through which decisions are discussed and made. The manager of Old St. Paul's advised that she can receive support from Programme Project managers, who are designated to assist the property manager when a large project is undertaken. Most recently, the case site has received a lighting and heating upgrade, supported by a developer from HNZ. The role of the manager at Old St. Paul's includes supervising the volunteers, a full time staff member, a few part time staff members, a visitor host and an employee who does the accounts and paperwork. The site has a 'Property Management Plan' which covers all areas of the site including volunteers, maintenance, marketing, public access visitor facilities and interpretation. This outlines current and future goals for the site, situated along an annual timeline.

A discussion in the interview about the interpretation section of this plan led to the question of whether there are guidelines for the presentation of the site and the interpretation given to its exhibition areas. It was revealed by the manager that there are no guidelines for the presentation

\footnotetext{
${ }^{3}$ All italicised words are the emphasis of the researcher, showing the key points in passages of direct quotation.

${ }^{4}$ NZHPT, Statement of Intent, 22.
} 
of Old St. Paul's and its interpretation. Ideas are discussed between the property manager, central region manager and national manager before finding a suitable place within the site for something new. Generally, a conservation architect would be consulted to ensure that the building fabric was stable and under no threats from the proposed exhibition or interpretation. Ensuring that any changes to the building or space are reversible is an important consideration. For example, the recently installed 'Read this building' interactive exhibition lent itself to the space formally occupied by a different exhibit and so was an obvious space. Features important for the space selection were whether the area was reasonably sound-proof for audio visual displays and unobtrusive to other visitors. As far as the site manager is aware, this is a national model, where the most important directives are to choose what is most appropriate for the property and what is in keeping with the heritage fabric, as well as making it attractive. Two examples given of other HNZ Heritage Destinations sites with recently installed interpretation are similar to Old St. Paul's - the development followed no set guidelines.

The manager described what the main themes or identities that Old St. Paul's presents to its visitors as follows:

It depends a little bit on people's interests, but the main things are the structure, the plain structure, the architecture of the place, which is unique in the world. You won't find a gothic revival style building in timber this size, so people would have never have seen anything quite like it. It's a lot about the colonial history, because it is a very very colonial building, the gothic revival was in full flight when the architect moved out here from England [...] and we are sitting on Màori reserve land, so parts of this were a thriving Māori pa. I guess that's always a really nice story to tell, a complicated story to tell too, that people were driven off the land in order to make this building possible. So especially European visitors who are into indigenous stories of New Zealand might come here and think it's just a European church, yes it is, but it is quite interesting because it is this distinctly colonial gothic, because it is not stone, and it is sitting on Māori land. Then, the Marines are very present here still, when they were stationed here during the Second World War, the Marines chose Old St. Paul's as their place of worship at the time and we have the original flags in the aisle that were left here after the war. One other thing that has become really popular are the textiles in the textile display, we've only had that for a few years, we have these large drawers and people can have a look at them and what is nice is that we are still using them according to the colours of the church year so they are still part of the collection that is used.

The main themes identified by the manager were the colonial gothic architecture, the colonial history, the Māori pa story, the US Marines and the textile display. A prominent feature of the 
church is the stained-glass windows, which were absent from the themes listed (an example of the windows can be seen in Figure Three). After I asked where these would be categorised, the manager placed the windows within the theme of colonial architecture. The manager also identified religion as a theme that is not prominent and not particularly present within the stories told at Old St. Paul's.

The manager thought that the themes identified were still representative and relevant to the site, although they were all pre-restoration and that the current presentation of the site was definitely still relevant and representative of the heritage stories. The manager identified religion as a theme that was no longer as relevant, because the site does not hold church services despite still being consecrated. Furthermore, the manager commented that she believes this will be an interesting theme:

Because this is something where the visitor expectation is quite different to what they might find, because not many realise that it is not a practising church so I could imagine that some people who don't get the whole story or context of the place may leave and think 'it's such a shame that there is nothing happening there' and I'm like 'gosh but there is so much happening here' but what they mean is that there are not services on a regular basis.

The site uses a number of interpretive tools to communicate the main themes and stories that are presented. For the site manager, the most important and valuable tools are the visitor hosts, who give personal and passionate visitor contact. Visitors can book for a guided tour of the site taken by these hosts. There are also the self-guide brochures available in a number of languages and the guide to the stained-glass windows. The American flags and textiles displays have interpretive panels. The focal exhibition, 'Read this building' offers audio visual information alongside items from the site's collection.

When asked if there was anything that she thought could be changed or revised, the reply was that the first 100 years could receive more focussed interpretation, alongside the significance of the land. A future project for the site is an oral history venture, led and funded by the 'Friends of Old St. Paul's' association. The results of the project would be used by the volunteers to look up information for visitors and to explore the social history of the building. 
In addition to identifying the themes that the site presents to visitors, I asked if there were any specific learning outcomes for visitors to the site. Although there are no HNZ learning outcomes, the manager has her own idea of what she would like visitors to leave with:

What is on display does determine what we would like them to take away. For us that is the uniqueness of the place, the survival, the heritage battle and also the uniquely colonial gothic building, sitting on Māori reserve land, this tricky bit of history, which is still very present, considering that we are bordering on the Marae.

As this is an important part of the management's presentation goals, I reiterated the three main points that the manager identified as specific learning goals for visitors:

So as manager what you would like the visitors to leave with from the interpretation and presentation you have got - those are the three main things: the uniqueness, the colonial gothic and the restoration story?

Yes, I would say so.

Furthermore, the manager believes that the current presentation and interpretation of Old St. Paul's effectively educates the visitors about the identified themes, if they have the time. Many of the visitors to this heritage site spend less than ten minutes in the building, as the stop is scheduled in an itinerary. For the visitor with more time and who is approached by a volunteer or visitor host, the manager is fairly confident that "they get across what they want to get across". Ideas for faster transmission of information are being discussed, including the use of audio guides and new technology in the hope that visitors with limited time can take away those learning outcomes.

Old St. Paul's does not currently use any methods to evaluate how effective their presentation and interpretation is in relation to the identified themes and identified learning outcomes. Old St. Paul's currently asks visitors to leave an email address which sends an invitation to participate in a visitor survey two to three weeks post-visit. It is a 'Get Smart' survey, from the Ministry for Culture and Heritage, tweaked to individual sites and used by most HNZ Heritage Destinations properties. The manager extracts data that is useful for marketing and leaves the remainder of analysis to the HNZ Head Office. The current survey does not ask about the presentation of the site or have questions relating to the exhibitions and interpretation. 
'Authenticity' is important to Old St. Paul's and the manager stated that staff can find it difficult to install new exhibitions and interpretation without losing some of the 'authentic' value. Old St. Paul's places emphasis upon retaining the originality of the architectural features and ensures that any exhibition and display is removable and does not detract from the overall genuine impression that the building gives. 'Authentic' value for visitors varies from person to person, but measurable importance is placed upon the palpable view of the originality of the building and the availability to interact with it. Items on display such as the brass memorial plaques illustrate the dilemma that the staff face; as although they add historic value, if new additions had not been suspended, they would all lose their 'authentic' value, as according to the manager they "would be plastered everywhere". The building itself is the main attraction, as the majority of visitor accessible space encompasses the original building. As stated by the manager during the discussion about interpretation, as long as exhibitions and interpretive panels are removable, the 'authenticity' is retained. The site is vigilant with repairs, ideally using the same materials. Sometimes this is not possible because of cost, but even with the tiles on the roof, they are particular in trying to keep the original look. In regard to communicating the 'authenticity' of the site to visitors, the manager acknowledges that there is always room for improvement. The two main points of contact for visitor education about the history and 'authenticity' of the structure are the volunteers and the 'Read this building' exhibition. As the site is reliant upon unpaid volunteers to boost staff levels, especially over weekends and holidays, the manager concedes that knowledge quality is sacrificed despite training. The videos in the exhibition are engaging and use a collection item to explore the wider context of the church and its history. However, in the manager's opinion, although the videos have been made well, the interpretation of the building's history and 'authenticity' is not outstanding.

The manager uses a variety of marketing tools to ensure that Old St. Paul's has a wide audience. As the site doubles as a heritage site and a function venue, different approaches are used for tourism, weddings and social media. Printed material is a large portion of the tourism advertising, with advertisements in travel guides, brochures and magazines. Usually the publications have an online presence which is also utilised. The distribution of print material includes the local i-site, the airport, the ferry terminals and on-board lounges. Although the site is used for an assortment of functions, weddings are the main revenue earner. Marketing for this 
side of the site includes attendance at wedding expos, corporate guides, printed material and a strong online presence. Wedding directory websites and Google advertisements are important tools. For specialised features such as the Christmas shop, a newspaper advertisement is an effective outlet. Old St. Paul's uses social media, which is updated on a regular basis. The site also has a dedicated webpage which combines all of the marketing information alongside the history of the site.

As discussed in the literature review, how a site is marketed can influence the opinion and expectations of visitors. However, the manager of the site does not believe that simultaneously advertising Old St. Paul's as a heritage site and a function venue is detracting from the heritage value. She believes that the function venue advertising, especially online, is not something that potential visitors or tourists will come across. The manager is of the view that by hosting functions, the site is presenting itself to a broader range of potential visitors:

They come here for a work function and walk through the door and it is nicely lit up for having dinner and they go, 'oh I forgot about that, I didn't know you could do this here, this is cool'. There are a lot of people who attend a function who will return, for them if this function was a work do, or a wedding, or a funeral, but was also a reminder that this is actually a really cool place of our identity, of our heritage which they knew existed, but it never occurred to them that they should go.

HNZ relies on self-generated funding. Sources include membership fees, property income, grants, interest and bequests. ${ }^{5}$ It has been forecast for the 2013-14 year that HNZ properties will raise $\$ 500,000$ through merchandising and $\$ 839,000$ through admissions and functions. ${ }^{6}$ Old St. Paul's is a heritage site that needs to generate additional revenue through hosting functions and providing the cathedral for venue hire. The manager believes that they juggle the two realms well:

You shut the doors on the last tourist at 5pm and you turn into something else a little bit. You still have people admiring the building but they didn't come here of their own choosing, they come for a particular band or a friend is getting married, but not because they've read about Old St. Paul's and want to check it out.

Many heritage sites are re-branding and focussing their marketing upon activities that will earn them additional revenue. As discussed in the literature review, this is a controversial move, with

\footnotetext{
${ }^{5}$ NZHPT, Statement of Intent, 28.

${ }^{6}$ Ibid.
} 
polarising opinions from academics and tourists alike. Old St. Paul's is an example of an iconic heritage site that sees alternative revenue generation as a necessity for on-going operation.

Furthermore, another controversial point is the gift store, located in the former vestry of the cathedral. The manager acknowledges that some visitors will find it inappropriate or uncomfortable as the cash register is close to the altar. However, unlike other heritage churches, Old St. Paul's does not charge an admission fee. The staff at the site would rather explain that the proceeds of the gift store sales fund repairs and maintenance, and that this method is preferable to an admission charge. The manager aims to market the gift store as part of the visitor experience by stocking branded items, souvenirs to do with the church or wooden crafts. A separate visitor centre to house the gift store, bathroom facilities, and other refreshment provisions would be welcomed by the manager at the site, although due to funding and council permits it is not a project for the near future.

Analysis of the data gathered to compile the management's perspective on the objectives and aims for the case study site reveal a complex and multidimensional organisation. There is no specific mission statement for the site, although the manager identifies that 'telling its story' is an important objective. A number of main themes for the presentation and interpretation were ascertained, including the architecture, the colonial history, the Māori pa story, the US Marines and the textiles. Three specific learning outcomes for visitors were identified as the uniqueness, the colonial gothic and the restoration stories. Retaining 'authentic' value and the originality of the building is important to Old St. Paul's and is a consideration for new interpretation and exhibitions. An awareness of the heritage status and tourism ventures of the site are situated alongside the necessity to earn additional revenue, to ensure that the site can function and undertake consistent maintenance.

\subsection{Visitor Understanding}

The following findings begin with the demographic data of the survey sample. Figure Nine and Tables One and Two give an overview of the characteristics of the survey participants. The sample population were heavily female, generally over the age of 50 and mostly international. The latest (1 January 2014) demographic data collected by Old St. Paul's corroborates my 
findings. Respondents to the 'Get Smart' survey were $62 \%$ female, generally over the age of 50 (the most represented age was $60-69$ at $33 \%$ ) and $70 \%$ were international visitors. ${ }^{7}$

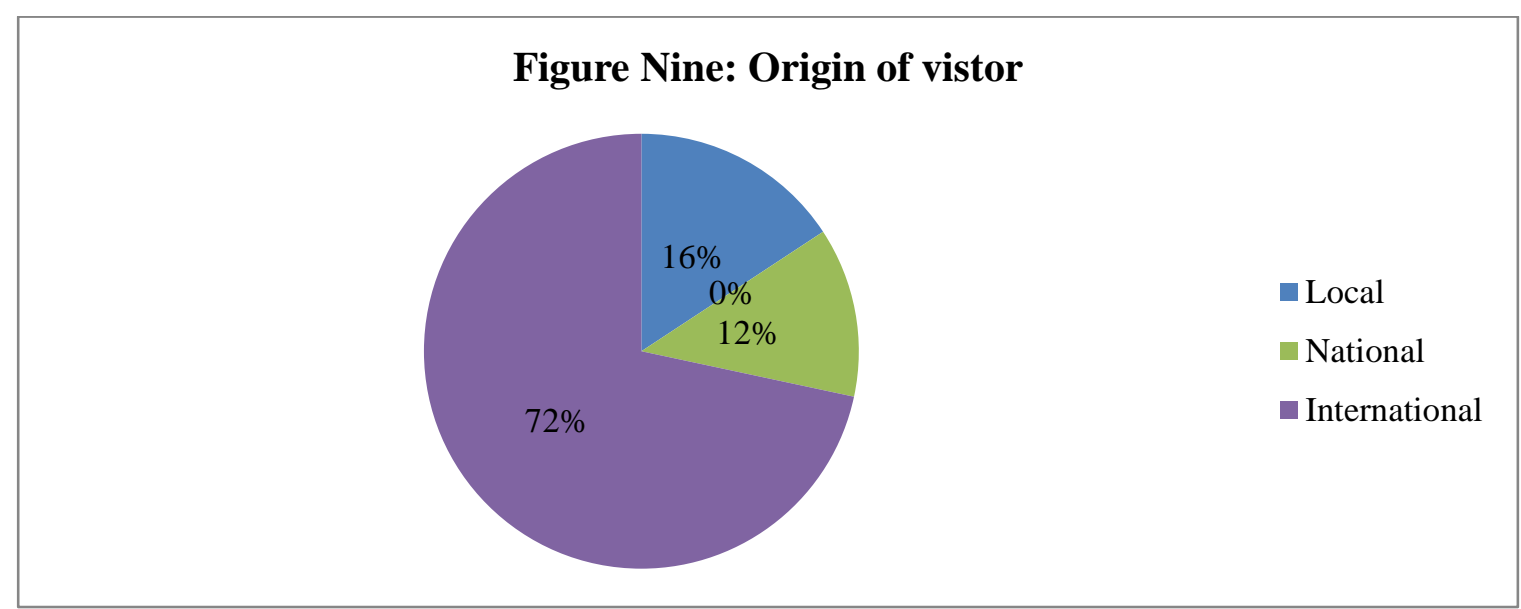

Figure Nine represents the origin of the survey participants, the 'regional' category on the survey was not identified with by any visitor. Table One shows the age groupings of the survey participants, and as in Figure Nine, there were two categories (30-34 and 45-49) that no visitor was associated with.

${ }^{7}$ Old St. Paul's, Get Smart, Ministry for Culture and Heritage, 2014, pp. 74-7. 


\section{Table One: Visitor age groups}

\begin{tabular}{|l|l|}
\hline Age group & Number of visitors \\
\hline $15-19$ & 1 \\
\hline $20-24$ & 4 \\
\hline $25-29$ & 2 \\
\hline $30-34$ & 0 \\
\hline $35-39$ & 1 \\
\hline $40-44$ & 1 \\
\hline $45-49$ & 0 \\
\hline $50-54$ & 6 \\
\hline $55-59$ & 2 \\
\hline $60-64$ & 3 \\
\hline $65-69$ & 5 \\
\hline $70+$ & 7 \\
\hline
\end{tabular}

Table Two: Visitor gender

\begin{tabular}{|l|l|}
\hline Male & $37 \%$ \\
\hline Female & $63 \%$ \\
\hline
\end{tabular}

The survey began by asking participants if they had visited Old St. Paul's before, and if 'yes', how many times they had previously been. Almost three-quarters (72\%) of the survey participants had not previously visited the case site. Of the $28 \%$ of visitors that had been before, $55 \%$ had visited more than seven times.

Figure Ten shows what response was given when asked how the survey participant had heard about Old St. Paul's. 'On a tour' and 'word of mouth' were the popular responses. As the sample population was mostly international, it is not unexpected that $37 \%$ of visitors arrived as part of a tour group. 


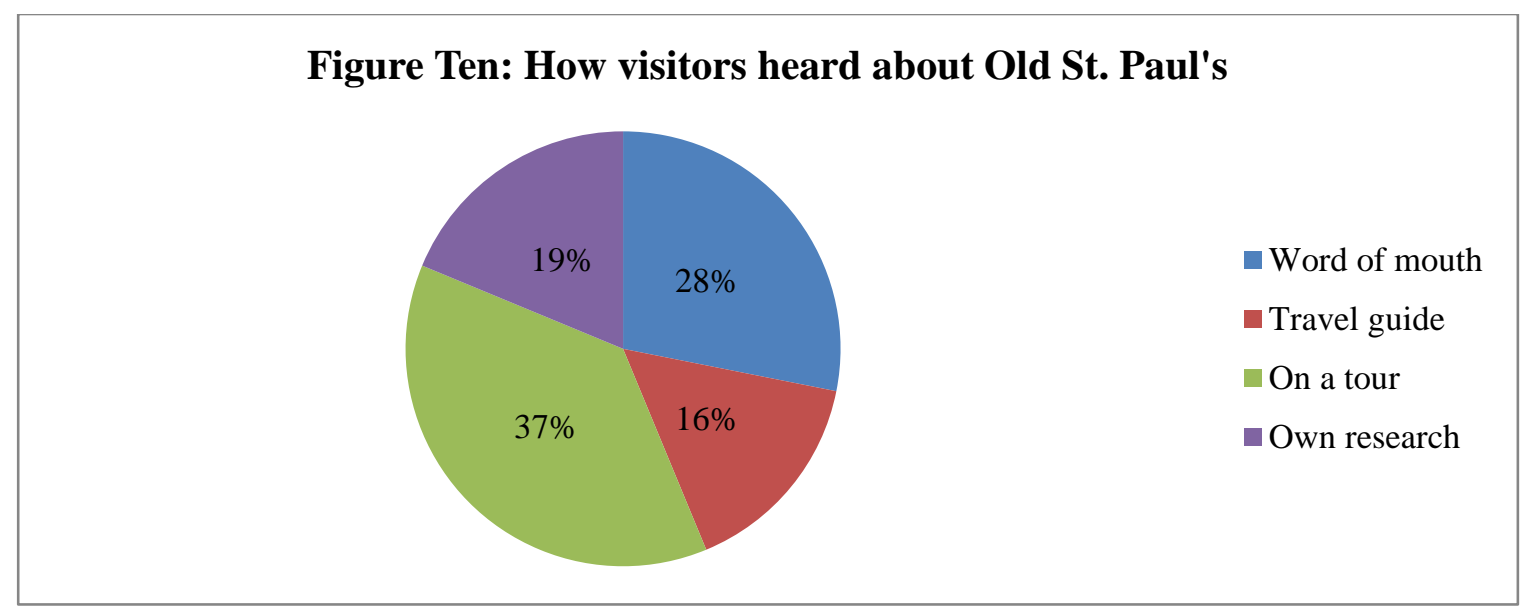

Figure Eleven shows the reasons given for visitation. Further to Figure Ten, the majority of visitors were at Old St. Paul's for tourism purposes.

Figure Eleven: Reason for visitation

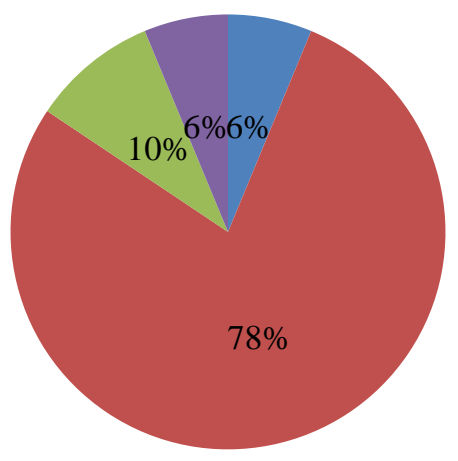

Showing friends and family

Tourism

Walking past

- Other

After determining how the participants had heard about the case site and the reason for their visit, the survey asked in what part of the church had the participant spent the most time. Seven main areas dominated these responses, of which the 'body of the church' was the most common answer, followed by 'the pews'. These two areas can be seen in Figure Six. The exhibition spaces were rated very low in this question. Figures Two, Four, Five and Seven show examples of the exhibition and interpretation areas at Old St. Paul's. As shown in Figure Twelve, areas of the church where there is interpretation were not where visitors spent the most time. 
Figure Twelve: Area's of Old St. Paul's where the most time was spent

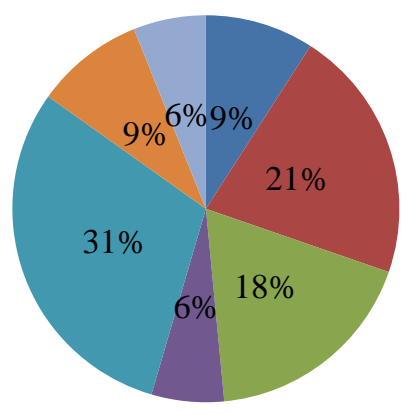

- Exhibition space

- Pews

- Altar cloths

- Stained-glass

- Body

- Altar

- Flags

Figure Thirteen shows the responses to what visitors liked about the areas in which they spent the most time. This was an open-ended survey question that I coded into six categories.

\section{Figure Thirteen: Responses to why participants spent the most time in a particular area}

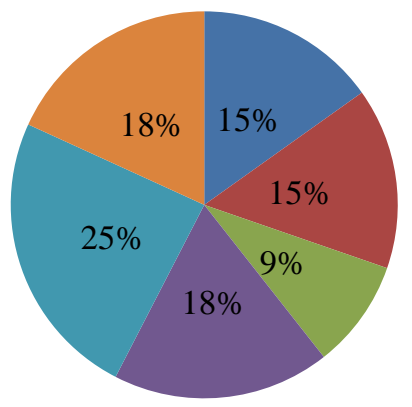

Liked the open space

- Wanted to sit down

Enjoyed the Stained Glass view

Could see the timber features

- Personal connection

The stories

The most frequent response was for a 'personal connection'. Comments from visitors that I coded into this category included: "I'm American and it was nice to learn the connection with World War Two soldiers" and "I'm interested in needle work, I make kneelers for my own church". Participants giving this answer had sought out areas important to them and their companions in which to spend the most time of their visit. The second most frequent response was 'the stories'. Comments from visitors that I coded into this category included: "I liked the stories in the videos" and "The interpretation taught me that the Japanese were so close, I hadn't realised they were a threat". Table Three shows that those who had spent the most time in the exhibition spaces did so because they were captivated by the stories being told. Table Three also 
shows all of the responses (as coded in Figure Thirteen) in correlation with the area the survey participant spent the most time in.

Table Three: Area's visitors spent the most time by reasons given

\begin{tabular}{|l|l|l|l|l|l|l|}
\hline & $\begin{array}{l}\text { Liked the } \\
\text { open } \\
\text { space }\end{array}$ & $\begin{array}{l}\text { Wanted to } \\
\text { sit down } \\
\text { Exhibition } \\
\text { space }\end{array}$ & $\begin{array}{l}\text { Enjoyed } \\
\text { view }\end{array}$ & $\begin{array}{l}\text { See timber } \\
\text { features }\end{array}$ & $\begin{array}{l}\text { Personal } \\
\text { connection }\end{array}$ & $\begin{array}{l}\text { The } \\
\text { stories }\end{array}$ \\
\hline Pews & $14 \%$ & $58 \%$ & & $14 \%$ & $14 \%$ & $100 \%$ \\
\hline $\begin{array}{l}\text { Altar } \\
\text { cloths/textiles }\end{array}$ & & & & & $100 \%$ & \\
\hline $\begin{array}{l}\text { Stained-glass } \\
\text { windows }\end{array}$ & & & $100 \%$ & & & \\
\hline Body & $40 \%$ & & & $40 \%$ & $10 \%$ & $10 \%$ \\
\hline Altar & & & $50 \%$ & $25 \%$ & $25 \%$ & \\
\hline Flags & & & & & $50 \%$ & $50 \%$ \\
\hline
\end{tabular}

From these figures, it can be seen that most visitors want to find a connection between themselves and the heritage. This is demonstrated by the large number of visitors who.spent the most time of their visit in areas of Old St. Paul's that offered a personal connection or where they could relate to the stories. The body of the church was a popular area because it gave the best view of the timber construction and carvings, although the same number of participants spent time here so they could sit down and watch others.

As shown in Table Four, no survey participants went on a guided tour. Old St. Paul's offer guided tours to larger groups of visitors who inquire about this service, and there is not always the requirement to pre-book. There were no guided tours booked for the days that I was present. The majority of visitors did a self-guided tour (which includes using a stained-glass window guide), or wandered the site without any guides; only $12 \%$ of participants had spoken with a visitor host. 
Table Four: Tours

\begin{tabular}{|l|l|}
\hline Type of tour & Percentage of visitors who went on this tour \\
\hline No tour & $30 \%$ \\
\hline Guided tour & $0 \%$ \\
\hline Self-guided tour & $58 \%$ \\
\hline Spoke with staff & $12 \%$ \\
\hline
\end{tabular}

The survey asked participants to identify any exhibitions that they had seen throughout their visit and $88 \%$ of visitors identified an area of exhibition at the case site. Almost half of this group (44\%) gave more than two examples of exhibitions. From the responses to this question, five main areas of exhibition were identified by the participants. Figure Fourteen shows the form of exhibition identified and the percentage of survey participants who saw it.

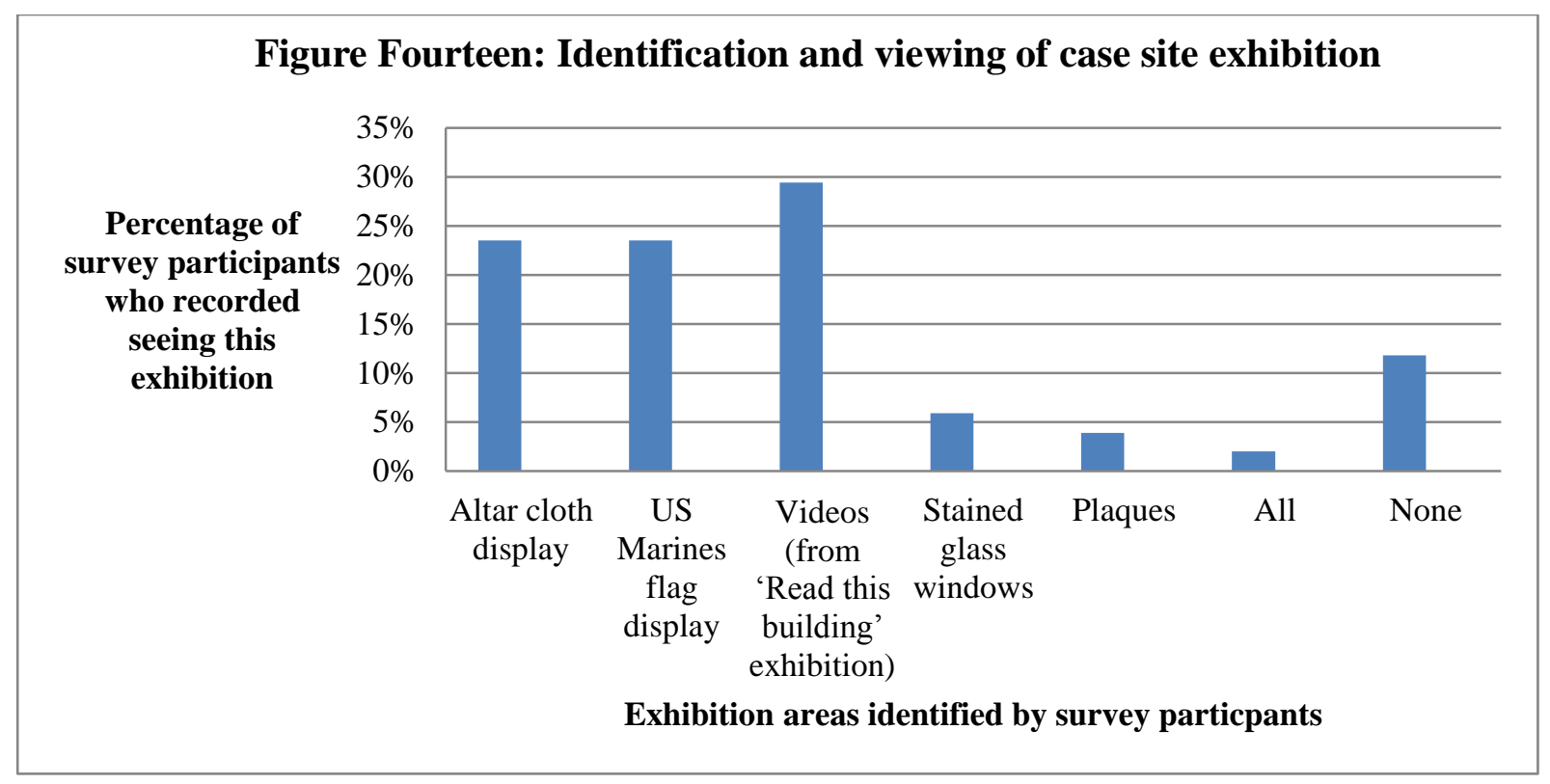

Interestingly, only $6 \%$ of participants identified the stained glass windows as an area of exhibition, although every visitor is exposed to the windows upon entry to the site. The windows were identified by the manager as a part of the colonial history presentation of the building. Furthermore, $12 \%$ of participants recorded that they did not see any form of exhibition, despite five areas being identified by other visitors. 
Of the $88 \%$ of people who identified an area of exhibition, three stories emerged as being associated with Old St. Paul's. Figure Fifteen outlines these stories.

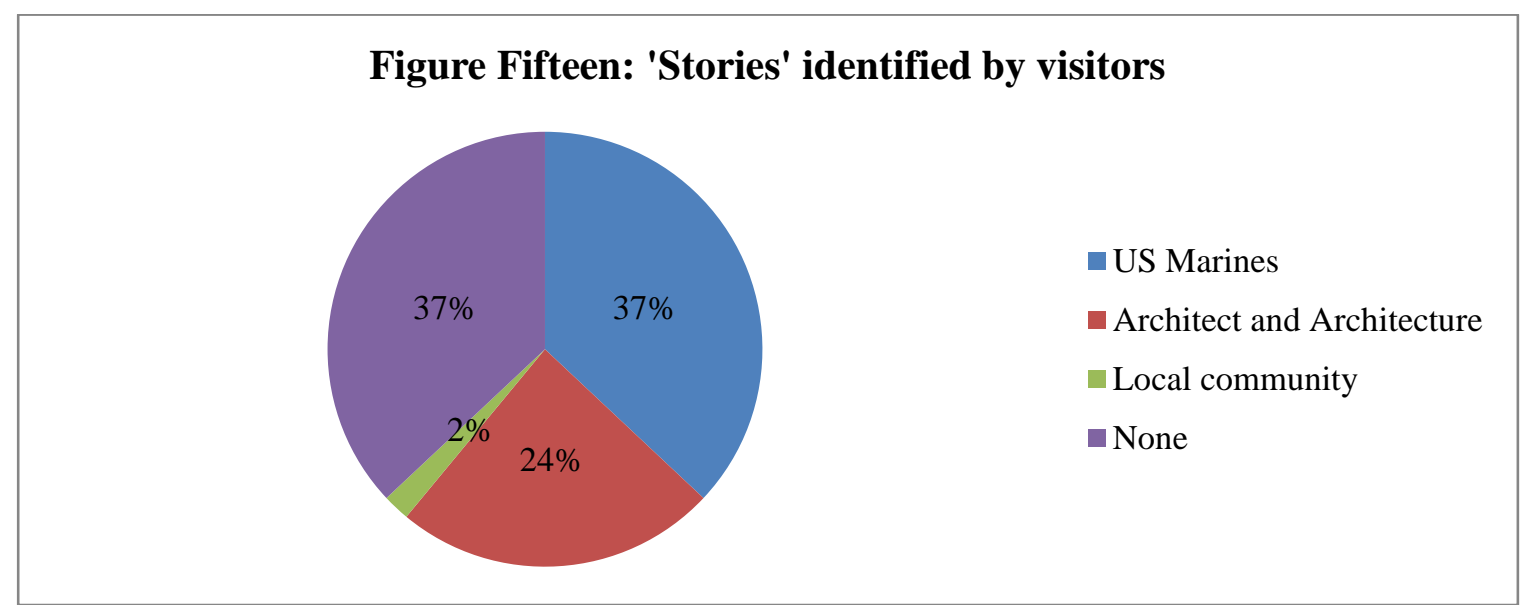

Almost $40 \%$ of people who identified a form of exhibition within the case site also stated that they saw no stories on display. This finding points to a discrepancy between areas of importance within the heritage site, and the stories that are associated with them. While visitors may notice or identify particular areas of relevance to the site and its heritage, as Figure Fifteen shows, almost half of the visitors ('none') are unable to associate particular stories with them. However, this could also indicate that while visitors see or visit the exhibition area, they do not necessarily read or watch the associated stories.

Visitors who identified an area of exhibition were asked to rate the effectiveness of the interpretation for educating them about Old St. Paul's. On a 1 to 5 scale (1 being 'very ineffective', 5 being 'very effective') the mean response was 3.8. This number was calculated by adding together all of the ratings given (from 1 to 5), and dividing the total by the number of participants who answered the question. The result is a positive indication that the current interpretation used by the case site is considered reasonably successful by the visitors. When asked for the reason behind their scale rating, 52\% of participants replied that the interpretation they had seen was 'clear and informative'. Only 15\% of responses were negative, stating that there was 'too much text' to read. A further $15 \%$ did not notice any interpretation; however these participants had answered 'none' or 'flags' to question 8. This suggests that people are not 
interested, or have not looked around enough to see any exhibitions and that the US Marines 'flag' interpretation panel is easily missed.

Table Five shows the responses of participants when asked for their opinion on the presentation of the church. Over $80 \%$ of the replies were 'beautiful' or 'very nice'. Of 32 survey participants, only one thought that the presentation of Old St. Paul's was 'authentic'.

Table Five: Overall presentation of Old St. Paul's

\begin{tabular}{|l|l|}
\hline Description used by participant & Percentage of participants who used this description \\
\hline Beautiful & $53 \%$ \\
\hline Very nice & $28 \%$ \\
\hline Good & $16 \%$ \\
\hline 'Authentic' & $3 \%$ \\
\hline
\end{tabular}

Figure Sixteen shows the responses to the subsequent question, which asked for the highlight of the participants visit.

Figure Sixteen: Highlight of visit

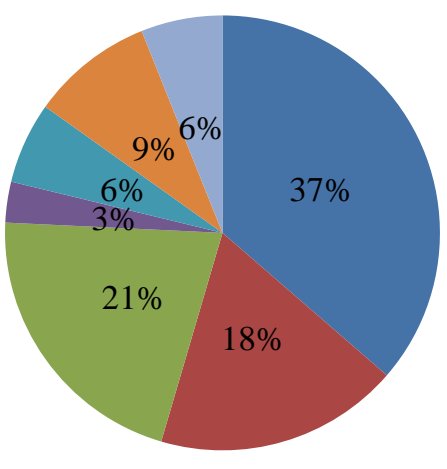

Architecture

Nothing in particular

Everything

- Videos (from 'Read this building')

US Marines flags

Altar frontals/textiles

- Stained-glass windows

A question which posed some difficulty asked whether visitors' expectations of Old St. Paul's had been exceeded, were met, or not met (below expectations) at the conclusion of their visit. As the majority of visitors gave 'tour group' as their reason for visiting, they had no prior expectations as it was a scheduled stop in a very busy itinerary. However, $75 \%$ said that their expectations had been met and $25 \%$ said their expectations had been exceeded. No survey 
participant gave 'below' as an answer. Furthermore, the subsequent question asked if the visitor had any recommendations for the site, for which $72 \%$ answered 'no'. However, the remaining $28 \%$ of participants had suggestions which ranged from logistical improvements such as clearly labelled exits, to further preservation and holding more church services.

The literature review highlighted that commercialisation such as gift stores can be contentious areas at a heritage site. However, this did not seem to be a problem at Old St. Paul's, with just over half of the visitors surveyed having been to the gift store, or were intending to visit the gift store. When asked if they were likely to return to Old St. Paul's, the mean response ${ }^{8}$ on a 1 to 5 scale ( 1 being 'not likely' and 5 being 'very likely') was 3.5. International visitors were asked of this likelihood on the basis that they were on a return trip to Wellington.

The findings from the visitor surveys show that the majority of visitors to Old St. Paul's can identify areas of exhibition. The issue highlighted by the surveys is that of the visitors who identify exhibitions, not all can recognise a story being told through the interpretation. The overall presentation of the site is positive, as more than $80 \%$ of visitors used 'beautiful' or 'very nice' to describe the building. Although visitors were not directly asked about 'authenticity', the 'authentic' value of the site was only referred to by one of the survey participants. Most of the visitors were international and had not visited before, confirming the demographic described by the manager.

\footnotetext{
${ }^{8}$ As previously discussed, this number was calculated by adding together all of the ratings given (from 1 to 5), and dividing the total by the number of participants who answered the question.
} 


\subsection{DISCUSSION}

\subsection{Case Study Evaluation and Comparison}

To reiterate, the primary question of this research asks if New Zealand heritage sites are providing exhibitions, interpretation and stories that successfully communicate the site management's presentation goals to visitors. The aim is to compare the presentation and interpretation goals and objectives of heritage site management with visitor understanding of the site. The presentation includes the marketing and the interpretive tools used externally and onsite. Evaluation of this relationship will determine whether or not the presentation goals outlined by site managers are being met. The findings from the different methods employed to evaluate this relationship between management and visitors at Old St. Paul's will be compared below and discussed in regard to the secondary questions and objectives.

Firstly, the interview with the case site manager identified site objectives, presentation and interpretation goals specific to the heritage site. Together with the NZHPT [HNZ] SoI and the specific Heritage Destinations aims, an overall view of the objectives and goals for Old St. Paul's has been constructed. I propose that the mission of Old St. Paul's, composed from the above named sources would be to:

Engage visitors in an experience that increases their understanding of New Zealand's past, New Zealand's cultural identity and, for New Zealanders, their place within it; this is achieved through experiencing heritage and having access to the stories that explain their significance.

Secondly, this mission helps to understand the collective past and develops an appreciation of the value of heritage and leads to their conservation for the benefit of both past and present future generations.

Telling stories is an important feature of Old St. Paul's and this is reiterated by the site manager as a goal for the interpretation. The main themes or areas of interpretation identified by the manager that Old St. Paul's presents are the architecture of the place, the colonial history, the Māori reserve land and indigenous stories, the US Marines and the textile display. Although there are no HNZ learning goals, the manager also identified some site specific goals for the presentation and interpretation. In addition to the stories outlined, the manager places emphasis upon three main stories that she has as specific learning outcomes for visitors. These are: the 
story of the uniqueness of the building, the colonial gothic story and the restoration story. From this analysis of the management sources, the overall mission, presentation and interpretation goals for the heritage site are evident and form the beginning of the case site evaluation. Analysis of the survey findings reveals that the majority of visitors to the site have not visited before, have not been exposed to marketing and most do not have preconceived expectations of their visit. The highest reason for visitation was tourism as part of a tour group and this highlights the important role that Old St. Paul's is playing as a New Zealand tourist destination. The areas of the church that have exhibitions are not the most popular and visitors do not spend a lot of time there. The surveys found that visitors prefer to spend their time where they can find a personal connection with the heritage. As $88 \%$ of visitors could identify an area of exhibition, it can be said that the exhibitions provided are accessible and easily recognised.

Five areas of exhibition were identified by visitors and these were: the altar cloth display, the US Marines display, the videos from the 'Read this building' exhibition, the stained-glass windows, and the plaques. Three stories emerged as being prominent to visitors from these areas and these are: the US Marines, the architect and the architecture and the local community.

For a simple and visual comparison, each side of the research question is represented in Tables Six and Seven below.

Table Six: Comparison of exhibitions/themes at Old St. Paul's

\begin{tabular}{|l|l|}
\hline Exhibitions/themes identified by management & Exhibitions/themes identified by visitors \\
\hline Altar cloth/textile display & Altar cloth/textile display \\
\hline Architecture & Plaques \\
\hline Colonial history & 'Read this building' exhibition videos \\
\hline Māori reserve land & Stained-glass windows \\
\hline US Marines display & US Marines display \\
\hline
\end{tabular}


Table Seven: Comparison of management and visitor stories at Old St. Paul's

\begin{tabular}{|l|l|}
\hline Stories identified by management & Stories identified by visitors \\
\hline Colonial gothic features & Architect and Architecture \\
\hline Uniqueness of the building & Local community \\
\hline Restoration story & US Marines \\
\hline
\end{tabular}

The highlighted cells in Table Six reveal that of five identified areas of exhibition and themes at Old St. Paul's, two are consistent between the management and the visitors. Table Seven shows that the learning outcomes that the manager of Old St. Paul's wishes for visitors to leave with are not predominantly identified by visitors. The 'architect and architecture' story identified by visitors is loosely comparable to the 'colonial gothic features' story, although the comments made by visitors in regard to the architecture were superficial. Although the manager identified all of the above stories, the analysis reveals that the exhibitions identified by the visitors do not tell the stories that the manager wants them to leave knowing. Visitors seem to respond to and remember the specific and smaller details of the exhibitions and their interpretation, rather than the overall presentation of stories about the heritage site. Therefore, to answer the research question, the presentation and interpretation goals of the Old St. Paul's management are not entirely aligned with visitor understanding of the site. There is a discrepancy between what themes or stories management are presenting to visitors, and what themes and stories visitors are taking away. The majority of visitors acknowledge and identify what exhibition spaces the management have presented; however, the main themes of the management are being missed by visitors in favour of smaller and more specific content. Analysis shows that the interpretation and presentation at Old St. Paul's does not effectively communicate the specific learning goals of the site, although the interpretation does get across the individual and specific stories. This is most likely because the outcomes identified by the management are not detailed in small exhibition/interpretation spaces such as the stories that are identified. Perhaps it is assumed that such major stories are inherent in the building and its presentation.

The presentation of the site includes the marketing and interpretive tools used by the management. The marketing of Old St. Paul's encompasses a variety of media and messages as the manager aims to reach a wide audience. Tourism and function venue hire are the main 
features of the site's marketing. The presentation of the site through both of these areas is reasonably similar, as the uniqueness of the site is the main highlight. The manager sees no issue with how the site is currently marketed and does not expect any controversy over simultaneously marketing Old St. Paul's as a heritage site and a function venue. Furthermore, acknowledgment of external site marketing was not given as a reason for visitation and so was not applicable in regard to a comparison of how the site was perceived.

Part of the interpretation experience is the tools used by the management to communicate the themes and stories. Visitors' to Old St. Paul's considered the interpretation and its tools effective for educating them about the appropriate story. This shows that when visitors are attracted to an exhibition space, the current interpretation tools used are successful and generally helpful to visitors. Although this is an area that should be periodically evaluated, at this stage this is not an area of Old St. Paul's that currently needs re-designing. Considering that there are no guidelines for the construction of interpretation, the management of Old St. Paul's have produced educational and effective exhibition spaces.

\subsection{Secondary Questions}

The secondary questions were answered through the findings and analysis of the interview and survey data. There are no presentation and interpretation guidelines for the case study site and all presentation and interpretation decisions are made internally and are not subject to a model or system. There is also no current evaluation for the interpretation. As discussed there is no specific mission statement for Old St. Paul's, by association the site is included in the general, nationwide missions and objectives found in the SoI. The visitor learning outcomes were stated by the manager and have been used in the construction of the comparison found in Tables Six and Seven. The majority of visitors are very impressed by Old St.Paul's and the overall impression can be considered as positive. However, the answers to a survey question which asked visitors for suggestions showed that while overall the site commands a striking first impression, upon reflection visitors can be disappointed that the cathedral is no longer operational in a religious fashion. 


\subsection{Objectives}

I created a mission statement for Old St. Paul's for the purpose of gaining insight into the management objectives for the site. Constructed from the NZHPT [HNZ] SoI and manager's interview, the statement gives a purpose to, and measurable goals for the site. I hope that this mission statement demonstrates the significance of establishing objectives, mission statements or similar. It is useful for individual heritage sites to acknowledge their overall aims and goals and to refer to these for self-evaluation and on-going progress tracking.

By having a mission statement or a similar declaration of intention, heritage sites are giving themselves standards and goals to work towards. Evaluation of these allows for re-development, re-interpretation and re-presentation. Even if a mission statement is not feasible, regular goal and target setting for management staff, overall presentation and interpretation and site operations is a beneficial activity.

Old St. Paul's is a significant national heritage site as it represents a number of local and national identities. The perceived 'authenticity' of the site is an important feature to ensuring continual visitation and tourist attraction. The stories that are presented at the site construct visitor experience and knowledge of New Zealand. As demonstrated through the survey results, the exhibitions provided at Old St. Paul's are recognised by most visitors to the site. These visitors can also ascertain stories representing local and national identities. Although 'authenticity' is an important consideration for the management of the site, only one surveyed visitor stated that the site was 'authentic' to them. In this case study, as the building is the main heritage attraction, it is assumed that 'authenticity' is inherent in the visitor experience. This assumption is made on the basis of the comments made by visitors on the overall presentation and impression of Old St. Paul's to them.

The analysis of the research has shown that while Old St. Paul's provides educational interpretation, parts of the overall history of the site are not being told in an effective manner to the visitor. In most cases visitors can identify stories and themes within the interpretation and while the sample size was of a pilot volume, the surveys recorded consistent points of view from the participants. As the majority of surveyed visitors to Old St. Paul's had less than ten minutes 
to spend on-site, the interior interpretation would benefit from providing a succinct and memorable overall history of the site that explained the three main points identified as important by the management. The presentation of the site induces superlative adjectives from visitors, yet the word 'authentic' was barely mentioned. As previously discussed, this could be because the building commands an 'authentic' experience from its very presentation; there are no gimmicks or doubtful displays, the main attraction is the building itself. This would corroborate what HNZ hopes that visitors understand from their properties, as they are marketed as 'authentic, in their original settings'.

The manager stated in the interview that "if they had the time" visitors would be able to identify the exhibitions, interpretation and the stories they were telling. I think that the research has shown this, and due to the limited time many visitors have at the site, a multi-lingual and condensed site history would be an effective interpretation tool. A multi-lingual history would be practical as a majority of visitors to the site are international, and English is difficult to speak and read for them.

In response to concerns outlined by literature reviewed on heritage tourism, commoditisation is not an issue at Old St. Paul's; the marketing of the site as a function venue does not affect the visitors perception of 'authenticity', and few negative remarks were recorded in regard to the gift store. Although Old St. Paul's is a popular function venue, it seems that the perceived 'authenticity', presentation, interpretation and visitor experience are not compromised by this. As the literature suggested that visitor preconceptions made from advertising are important factors for determining a successful visit, it is assumed that these ideas are not being challenged at Old St. Paul's.

The surveys highlighted a number of points that are topical in heritage tourism literature. Most tourists want to visit a heritage site that can offer them a slice of their own history and can present the opportunity for nostalgic contemplation. The prevalence of survey participants who wanted to find a personal connection at Old St. Paul's demonstrates the importance of heritage sites stimulating individual reflection through their exhibitions and interpretation. As New

\footnotetext{
1 “Home."
} 
Zealand encourages and receives an increase of heritage minded visitors, research such as this pilot investigation is important for gauging how New Zealand is perceived by these tourists. Marketing campaigns can promise a particular type of experience, furthered by claims such as that made by HNZ regarding 'authenticity', national identity and quality. Current heritage evaluation declines to consider the management/visitor relationship, which as shown through this research is a contender for providing quality data that can be used across industries.

This research has also revealed that heritage literature needs to consider the distinction between exhibitions, interpretation, displays and information panels at heritage sites. For the purpose of my research I grouped these items all as 'exhibitions'. However, there are significant differences between these items (such as content, object context, the use of multi-media etc) and yet most are categorised together in the literature as 'interpretation'. This came to my attention when during the surveys I asked participants to name the exhibitions that they had seen during their visit. On many occasions I was required to prompt the participant with an obvious example such as the 'Read this building' exhibition before the visitor could give further examples. An implication of this is how survey questions are worded so that the researcher's intention is understood by participants. This experience demonstrates that there is no clear distinction of what interpretation heritage sites should be producing and at what information level. This poses difficulty for heritage sites to evaluate their presentation and interpretation goals as there is no standard to compare against. This suggests that further research could explore visitor perceptions of and preferences for different types of interpretation.

Furthermore, as stated by Warren and Taylor, the majority of heritage tourism sites in New Zealand have classified themselves as such because they are located in a heritage building. As shown by this research, orchestrating a personal connection between the visitor and the heritage is an important feature of a heritage site. A heritage building alone is not necessarily enough to foster such a profound visitor experience. I believe that a refinement of the definition of a heritage site would benefit the heritage industry in New Zealand, and defining factors should include 'authenticity', the construction of identity and quality interpretation and experience. 
In corroboration with heritage management theory, this research has shown the validity of heritage sites having a mission statement, and the importance of goal setting and periodic evaluation. As the significance of visitor experience and the monitoring of such has been documented by the Ministry of Tourism, it is hoped that other heritage tourism sites will adopt similar approaches. The 'quality revolution' has placed more power in the hands of the consumer so continuous quality improvement has become a matter of survival for all organisations in the heritage sector. ${ }^{2}$ Heritage sites that construct and present any identity significant to New Zealand are responsible for the education of their visitors. In order to ensure that the visitor experience is successful, evaluation of the site's interpretation and displayed stories are integral to the continuation of successful heritage tourism in New Zealand.

\footnotetext{
${ }^{2}$ Siobhan Drummond and Ian Yeoman, Quality Issues in Heritage Visitor Attractions (Oxford: ButterworthHeinemann, 2001), 14.
} 


\subsection{PRACTICAL MANAGEMENT RECOMMENDATIONS FOR OLD ST. PAUL'S}

These recommendations are general observations taken from the survey results and are intended to provide some basic ideas to remedy the areas that may benefit from additional execution. It is not an exhaustive list, but proposes a number of suggestions to increase visitor and site evaluation, target specific learning outcomes and to diversify and increase visitor numbers.

1. Construct and implement specific presentation and interpretation guidelines (including a mission statement) for Old St. Paul's, as these would enhance the quality of the exhibitions and interpretation (a nation-wide HNZ guideline would also be beneficial). This would also allow for structured and periodical evaluation to take place. Furthermore, regular goal and target setting for management staff in regard to the overall presentation, interpretation and exhibition effectiveness would be a valuable activity.

2. When staff resources permit, undertake regular visitor surveys which evaluate visitor perception of interpretation, presentation and 'authenticity'. These can be short, casual and easily analysed, yet contribute to the continual evaluation of Old St. Paul's main interpretation and exhibition features. Alternatively, as visitors are already prompted to leave their details for an online survey, leaving a short survey at the information desk would be time and resource effective.

3. Revise the current interpretation to emphasise the learning objectives and stories that were outlined in the manager's interview. The visitor surveys showed that the critical learning outcomes were not particularly coherent or obvious for all visitors.

4. Invite local groups, schools, function guests etc to contribute ideas for presentation, interpretation, exhibitions and projects; as an active and greater community presence could increase visitor numbers and function bookings from currently underrepresented groups such as those 'just walking past' and local and regional visitors. 
5. Additionally, increasing community engagement by offering a traveling exhibition or succinct presentation of Old St. Paul's as part of local history group seminars and school education programmes would encourage a wider range of people to visit. Furthermore, concurrently advertising the guided tours at such events may appeal to a different demographic of visitor as according to the visitor surveys this option is currently under-utilised and can provide a revenue income.

6. The survey results highlighted that visitors like to find a personal connection when visiting Old St. Paul's. A review of the history of the building and its interactions with different nationalities and representative groups (particularly in recent history) could provide further material for new interpretation of the space that will attract a wider audience.

7. Local and domestic visitors were the least represented visitor groups. A targeted campaign to advertise Old St. Paul's to this group of travellers could increase visitor numbers and contribute to better 'word of mouth' national advertising.

8. Similarly, the most represented age group was 50 plus (who were mostly travelling with a tour group). Attracting a younger visitor range who travel independently will boost visitor numbers and reviews and recommendations will filter through to travel review websites, local hostels and backpackers. 


\subsection{CONCLUSION}

This dissertation crafted research to ask if heritage in New Zealand is providing exhibitions, interpretation and stories that successfully communicate with domestic and international visitors. The research explored the relationship between how a heritage site is presented by its management, and how visitors to the site understand this presentation. The presentation of the site included the analysis of the site's interpretation, exhibitions, marketing and the overall visitor impression. I was concerned that there was a gap in the management/visitor relationship reflecting a lack of strategic planning and evaluation at heritage sites. As perceived 'authenticity' and 'authentic' value is a valuable asset to New Zealand heritage and heritage tourism, I wanted to know how well heritage sites were communicating themselves to their audiences. 'Authentic' value, strategic planning and visitor evaluation are important features for New Zealand heritage sites, as they have been shown to portray national, regional and local identities to both domestic and international visitors. The case study, Old St. Paul's, demonstrated this gap to a degree, as there is no formal mission statement or evaluation of visitor understanding at the site.

The literature review highlighted that heritage is a growing sector of the international economy and yet can be considered 'false history', prominently as heritage sites commercialise in an attempt to cover operating costs. The review also outlined that heritage is vital in the construction of identity, emphasising the importance of interpretation for visitor understanding. Specifically in New Zealand, the Ministry of Tourism identified that retaining 'authentic' value at heritage sites was a priority of their strategic planning. Through the case study, I found that Old St. Paul's in Wellington is a nationally significant heritage site that presents a number of historical and social stories to its visitors. The site did not currently use any methods to evaluate the effectiveness of what it was presenting to its visitors through the exhibitions and displays. The research showed that the majority of visitors to the site are international and have not visited before. This was also shown in the reason for visitation, of which tourism as part of a tour group was the highest recorded response. This highlights the important role that Old St. Paul's is playing as a New Zealand tourist destination. 
Through mixed-methods of interviewing and surveys, I found that the current presentation and interpretation used by the management of this site was reasonably effective at educating the visitors about local and national stories. I would encourage other nationally significant heritage sites to evaluate their own exhibitions and interpretation to understand what their visitors are leaving with. Although the results may confirm managerial assumptions, such research can assist with writing a site mission statement or refining site objectives. Such data can be used for marketing or to redesign parts of the site's story-telling areas.

As a pilot investigation there are some limitations to this research. Research in this area could benefit from further case studies sampling a larger visitor portion to evaluate whether other high profile New Zealand heritage sites are also operating in a similar fashion. As the pilot survey is standardised, the opportunity exists for multiple individuals to carry out the research which would greatly increase the sample size. Furthermore, heritage sites outside of HNZ would be interesting to research as they would offer a different management perspective. As there are no formalised guidelines for the operation of heritage sites, independently run sites, council sites and sites run by the Department of Conservation may show very different results. The research also offers some considerations for the development of this pilot. A mixed-methods approach, whilst benefiting and enhancing the research is time consuming. This is a factor that especially small heritage sites would need to consider. The season of when the research takes places also needs to be thought about, as although the inclusion of cruise ship passengers raised the survey sample in this pilot, heritage sites would need to be aware that the season will affect and possibly skew any research results. Many participants of this research were part of large groups that descended upon the case study site in waves. Many of these tour groups were also time restrained. Such visitor patterns need to be taken into account when considering survey research; as in the time period given to such visitors, although there may be more than 30 at one time, it is only possible to survey one or two. As discussed earlier, the wording and definitions used in a survey are very important, and what is to be included as exhibitions and interpretation needs to be decided and adhered to.

It is hoped that this research has contributed to heritage tourism in New Zealand by offering a pilot study that can be developed and adapted by heritage sites. The questions asked in this 
research have identified that themes such as 'authenticity', national identity and visitor experience are integral parts of the New Zealand heritage industry; and that the understanding both domestic and international visitors leave with are important consideration for heritage managers. The evaluative model used of a management/visitor relationship can be utilised throughout the heritage industry to enhance and maintain successful visitor experiences. 


\subsection{APPENDICES \\ 9.1 Appendix One: Visitor Survey for Old St. Paul's}

\section{Old St. Paul's Survey}

$\mathrm{Hi}$, my name is Elise Caddigan. I'm a student on the museum and heritage studies programme at Victoria University and I am currently undertaking research for my Masters dissertation. I noticed you spent some time in Old St. Paul's and I would be interested in asking if you would like to be a part of my research and participate in a short survey. It will take about 10mins and I would be very grateful for your time.

(If they agree ...)

Thanks for agreeing to speak with me. Anything you say is anonymous and confidential, and you may stop the interview at any time. There are no right or wrong answers - it is your honest opinion that counts. I have a copy of the Victoria University ethics statement on the project if you would like more information about this.

1. Have you been here before?

Yes No

2. (If yes) how many times?
$1-2$
$3-6$
$7+$

3. How did you hear about OSP?

(SocialMedia) (Newspaper) (Radio) (WordofMouth) (TravelGuide)

4. What is the main reason for your visit today?

(ShowingFaF) (Tourism) (Event) (Walkingpast)

5. In what area of OSP did you spend the most time?

(ExhibitionSpace) (Giftstore) (Pews) (Altarcloths) (Outside) (StainedGlass)

6. What did you like about this area? 
7. Have you been on a guided or self-guided tour?

No guided $\quad$ self-guided informally spoke with staff

8. What exhibitions did you see?

9. Whose stories did you see on display at OSP?

10. On a scale of $1-5$, ( 1 being not informative and 5 being very informative) how would you rate the interpretations/exhibitions effectiveness for informing you about OSP?

$\begin{array}{lllll}1 & 2 & 3 & 4 & 5\end{array}$

What are the reasons for your ranking?

11. Overall, how do you feel about how OSP is presented?

12. What has been the highlight of your visit?

13. Has your overall visit to OSP exceeded, met or fallen below your expectations? Exceeded Met Below

14. Do you have any suggestions for OSP?

15. Have you visited the gift store? 
Yes No

16. Where are you visiting from?

Local Regional National International

17. On a scale of 1-5, (1 being not likely, 5 being very likely) how likely are you to return?

$\begin{array}{lllll}1 & 2 & 3 & 4 & 5\end{array}$

18. Which age range do you fall within?

$15-19 \quad 20-24 \quad 25-29 \quad 30-34 \quad 35-39 \quad 40-44 \quad 45-49 \quad 50-54 \quad 55-59 \quad 60-64 \quad 65-69 \quad 70+$

19. Male Female 


\subsection{Appendix Two: Information Sheet for Visitor Survey at Old St. Paul's}

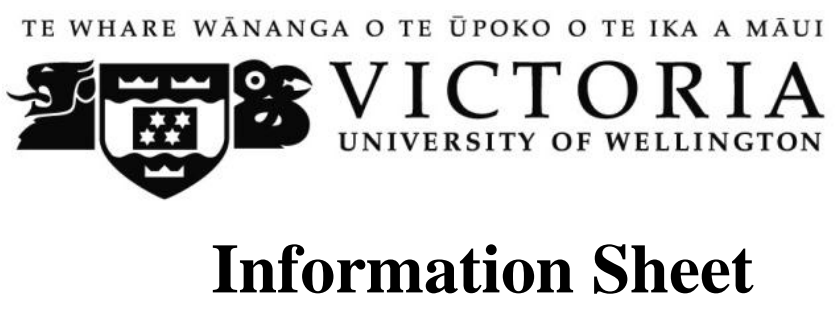

Management interpretation and visitor understanding at New Zealand heritage sites

Researcher: Elise Caddigan, Museum \& Heritage Studies student, Victoria University of Wellington

I am a Masters student in the Museum \& Heritage Studies programme at Victoria University of Wellington. As part of my dissertation I am undertaking a short survey of visitors to Old St. Paul's, Wellington. The aim of the dissertation is to compare the management interpretation and presentation at Old St. Paul's with the visitor understanding of the same interpretation and presentation at the case study heritage site.

The aim of this survey is to understand the visitor understanding of the presentation and interpretation at Old St. Paul's.

The short survey will be conducted entirely confidentially and it will not be possible for you to be identified personally. Anyone over the age of 15 is welcome to participate. All handwritten notes will be destroyed after the research has been analysed and written into the dissertation. By agreeing to participate in this research you are giving your informed consent. The dissertation will be submitted for marking to the Museum and Heritage Studies Programme and will be deposited in the University Library

This project has ethical approval from the Human Ethics Committee at Victoria University of Wellington. If you have any questions or would like to receive further information about the project, please contact my academic supervisor, Dr Lee Davidson, at Victoria University of Wellington, PO Box 600, Wellington, phone: +64 4463 5929, email: lee.davidson@vuw.ac.nz. Alternatively, I can be contacted at meyricelis@ myvuw.ac.nz.

Museum and Heritage Studies

School of Art History, Classics and Religious Studies

PO Box 600, Wellington, New Zealand

Phone +64-4-463 5928 Fax +64-4-463 5024

Email museum-heritage@vuw.ac.nz Website www.vuw.ac.nz/museum-heritage 


\subsection{Appendix Three: Information Sheet for the Manager of Old St. Paul's}

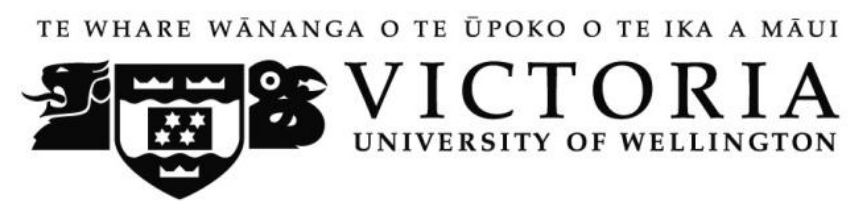

\section{Management interpretation and visitor understanding at New Zealand heritage sites}

Researcher: Elise Caddigan, Museum \& Heritage Studies Programme, Victoria University of Wellington

Hello,

I am a Masters student in the Museum and Heritage Studies Department at Victoria University of Wellington. I am conducting research as part of the requirements of my dissertation, and I would like to invite you to participate.

I am researching for a dissertation investigating the relationship between management presentation and interpretation and visitor understanding at the New Zealand heritage site, Old St. Paul's, Wellington. You have been invited to participate as you are the current manager of the case study heritage site, Old St. Paul's. If you decide to participate you will be asked to meet with me for an interview, to discuss how Old St. Paul's is managed, the presentation and interpretation aims for the heritage site; and your opinions on the current presentation, interpretation, learning outcomes for visitors and functions and events the site hosts.

In particular we will discuss your views and opinions as the manager of the heritage site, to be used in comparison to the visitor surveys I will also be conducting. The meeting can take place at your place of work if appropriate, at a mutually agreed upon time, and should take approximately one hour. With your permission, the interview will be recorded for my use so that I can review the information you provide. The recording will transcribed and sent to you for checking and editing before being reviewed by myself.

Due to the nature of the investigation anonymity is not possible. As the job position you are employed in will be used ("The Manager of Old St. Paul's") in the published material, it will be possible for a connection to be made to your name.

Museum and Heritage Studies

School of Art History, Classics and Religious Studies

PO Box 600, Wellington, New Zealand

Phone +64-4-463 5928 Fax +64-4-463 5024

Email museum-heritage@vuw.ac.nz Website www.vuw.ac.nz/museum-heritage 
Only the transcript edited by yourself will be used in the publication and every effort will be made to ensure that you are content with the results of this. The results of the research will be discussed in my dissertation but all source study information will be kept in a secure location. Taking part in the research is your decision. You do not have to be in this research if you do not want to. Should you feel the need to withdraw from the project, you may do so without question at any time before the $30^{\text {th }}$ of November 2013. You may also decide not to answer any question you are not comfortable with. The Human Ethics Committee has granted approval for this project.

No other person besides my supervisor, Dr Lee Davidson, and I will have access to the data. Recordings and transcripts will be destroyed once the dissertation has been marked.

The dissertation will be submitted for marking to the Museum and Heritage Studies Programme and will be deposited in the University Library. I will be happy to answer any questions you have about the study. You may contact me at meyricelis@myvuw.ac.nz, or my research supervisor, Lee Davidson, lee.davidson@vuw.ac.nz if you have course related questions or problems.

Thank you for your consideration.

Kind regards,

\author{
Elise Caddigan \\ 0273211743 \\ meyricelis@myvuw.ac.nz \\ Lee Davidson \\ Senior Lecturer \\ Museum \& Heritage Studies \\ 044635929 \\ lee.davidson@vuw.ac.nz
}

\footnotetext{
Museum and Heritage Studies

School of Art History, Classics and Religious Studies

PO Box 600, Wellington, New Zealand

Phone +64-4-463 5928 Fax +64-4-463 5024

Email museum-heritage@vuw.ac.nz Website www.vuw.ac.nz/museum-heritage
} 


\subsection{BIBLIOGRAPHY}

Aas, Christina, Adele Ladkin and John Fletcher. "Stakeholder Collaboration and Heritage Management." Annals of Tourism Research Vol. 32, No. 1 (2005): 28-48.

Alexander Turnbull Library, Wellington, New Zealand. "Williams, William, 1859-1949. St Paul's Anglican Church in Mulgrave Street, Thorndon, Wellington." Accessed 17 January 2014. http://natlib.govt.nz/records/22748744

Austin, Nathan K. "Managing Heritage Attractions: Marketing Challenges at Sensitive Historical Sites." International Journal of Tourism Research Vol. 4, No. 6 (2002): 447-457.

Beeho, A. J. and R. C. Prentice. "Conceptualizing the experiences of heritage tourists: A case study of New Lanark World Heritage Village." Tourism Management Vol. 18, No. 2 (1997): 7587.

Bircham, Deric N. Old St. Paul's: An Illustrated Essay. Wellington: A. H \& W. Reed Ltd, 1981.

Black, Graham. "Hows of concept design." in Quality Issues in Heritage Visitor Attractions, edited by Siobhan Drummond and Ian Yeoman, 121-135. Oxford: Butterworth-Heinemann, 2001.

Black, Graham. "Whats, whys and whos of concept design." in Quality Issues in Heritage Visitor Attractions, edited by Siobhan Drummond and Ian Yeoman, 100-120. Oxford: ButterworthHeinemann, 2001.

Blockley, Marion. Heritage Interpretation. New York: Routledge, 2006.

Burnett, Katherine A. "Heritage, authenticity and history." in Quality Issues in Heritage Visitor Attractions, edited by Siobhan Drummond and Ian Yeoman, 39-53. Oxford: ButterworthHeinemann, 2001.

Collier, Alan and Sue Harraway. The New Zealand Tourism Industry. Auckland: Pearson New Zealand, 2005.

Darlow, Susan, Stephen Essex and Mark Brayshay. "Sustainable management practices at visited heritage sites in Devon and Cornwall." Journal of Heritage Tourism Vol. 7, No. 3 (2012): 219237.

Davidson, Lee. "Visitor Studies: Towards a culture of reflexive practice and critical museology for the visitor-centred museum." in Museum Practice: Critical debates in contemporary museums, edited by Conal McCarthy. Wiley-Blackwell, forthcoming 2015.

Drummond, Siobhan. "Critical success factors for the organisation." in Quality Issues in Heritage Visitor Attractions, edited by Siobhan Drummond and Ian Yeoman, 16-38. Oxford: Butterworth-Heinemann, 2001. 
Drummond Siobhan and Ian Yeoman. Quality Issues in Heritage Visitor Attractions. Oxford: Butterworth-Heinemann, 2001.

de Vaus, David. Research Design in Social Research. London: SAGE Publications, 2001.

Fullerton, Leanne, Kathleen McGettigan and Simon Stephens. "Integrating management and marketing strategies at heritage sites." International Journal of Culture, Tourism and Hospitality Research Vol. 4, No. 2 (2010): 108-117.

Hall, C. Michael and Simon McArthur. Heritage Management in NZ and Australia: Visitor Management, Interpretation, and Marketing. Auckland: Oxford University Press, 1993.

Hall, C. Michael and Simon McArthur. Integrated Heritage Management: Principles and Practice. London: The Stationery Office, 1998.

Harrison, Richard. Manual of Heritage Management. Oxford: Butterworth-Heinemann, 1994.

Harrison, Rodney. "What is Heritage?" in Understanding the Politics of Heritage, edited by Rodney Harrison, 5-42. Manchester and New York: Manchester University Press, 2010.

Howard, Peter. “The Rise of Heritage.” Asian Anthropology Vol. 9 (2010): 1-27.

ICOMOS International Scientific Committee on Interpretation and Presentation. The ICOMOS Charter for the Interpretation and Presentation of Cultural Heritage Sites. Accessed 18 February 2014. http://www.enamecharter.org/downloads/ICOMOS_Interpretation_Charter_EN_10-04-07.pdf

Jameson, John. H. Jnr. "Presenting Archaeology to the Public." in The Heritage Reader, edited by Graham Fairclough, Rodney Harrison, John H. Jameson Jnr and John Schofield, 427-456. London: Routledge, 2008.

Jimson, Kerry. "Translating incomprehension into understanding: A case for interpretation." in Museum practice: The contemporary museum at work, edited by Conal McCarthy. Malden, MA: Wiley, forthcoming 2015.

Jones, Sian. "Experiencing Authenticity at Heritage Sites: Some Implications for Heritage Management and Conservation." Conservation and Management of Archaeological Sites Vol.11, No. 2 (2009): 133-147.

Laws, Eric. "Conceptualizing visitor satisfaction management in heritage settings: an exploratory blueprinting analysis of Leeds Castle, Kent." Tourism Management Vol 19 Issue 6 (1998): 545554

Lowenthal, David. The Heritage Crusade and the Spoils of History. Cambridge: Cambridge University Press, 1998. 
Marshall, Catherine and Gretchen B. Rossman. Designing Qualitative Research. California: SAGE Publications, 1999.

Masberg, Barbara A. and Lois H. Silverman. "Visitor Experiences at Heritage Sites: A Phenomenological Approach." Journal of Travel Research Vol 34, No. 20 (1996): 20-25.

Moore, Dallas. Old St. Paul's: The First Hundred Years. Wellington: Government Printer, 1970.

Moscardo, Gianna. "The shaping of the tourist experience: the importance of stories and themes." in The Tourism and Leisure Experience, edited by Michael Morgan, Peter Lugosi and JR. Brent Ritchie, 43-59. Bristol: Channel View Publications, 2010.

New Zealand Historic Places Trust. Statement of Intent 2013-16.

New Zealand Historic Places Trust. "Home.” Accessed 13 March 2014.

http://www.historicplaces.org.nz/?sc_lang=en

New Zealand Historic Places Trust. "Places to Visit." Accessed 10 April 2013. http://www.historicplaces.org.nz/placestovisit/lowernorthisland/oldstpauls/history.aspx?sc_lang= en

New Zealand Historic Places Trust. "Read this Building.” Accessed 10 April 2013. http://www.historicplaces.org.nz/exhibitionsandtours/readbuilding.aspx

New Zealand Ministry of Economic Development. "Seasonally adjusted visitor arrivals to New Zealand." Accessed 10 September 2014.

http://www.med.govt.nz/sectors-industries/tourism/image-library/tourism-research-data/ivayearly.png

New Zealand Ministry of Tourism. Tourism Strategy 2010. Wellington: Ministry of Tourism, 2001.

New Zealand Ministry of Tourism. Tourism Strategy 2015. Wellington: Ministry of Tourism, 2007.

Old St. Paul's. Get Smart. Wellington: Ministry for Culture and Heritage, 2014.

Patton, Q. Qualitative Evaluation and Research Methods. Newbury Park, California: SAGE Publications, 1990.

Poria, Yaniv, Avital Biran and Arie Reichal. "Different Jerusalems for Different Tourists." Journal of Travel and Tourism Marketing Vol. 22, No. 3/4 (2007): 121-138.

Poria,Yaniv, Arie Reichel and Avital Biran. "Heritage Site Management: Motivations and Expectations." Annals of Tourism Research Vol. 33, No. 1 (2006): 162-178. 
Pratt, Adrian. “Old St. Paul's.” Accessed 17 January 2014.

kiwiscots.blogspot.com

Schofield, John. "Heritage Management, Theory and Practice." in The Heritage Reader, edited by Graham Fairclough, Rodney Harrison, John H. Jameson Jnr and John Schofield, 15-30. London: Routledge, 2008.

Seba, Jaime A. Tourism and Hospitality: Issues and Developments. Point Pleasant, New Jersey: Apple Academic Press, Inc., 2012.

Shenton, Andrew K. "Strategies for ensuring trustworthiness in qualitative research projects." Education for Information Vol 22 (2004): 63-75.

Sørensen, Marie Louise Stig. "Between the lines and in the margins: Interviewing people about attitudes to heritage and identity." in Heritage Studies: Methods and Approaches, edited by M. L. Stig Sørensen and J. Carman 164-177. London: Routledge, 2009.

The Department of Conservation. Increasing public engagement with historic heritage. Wellington: The Department of Conservation, 2009.

Tildon, Freeman. Interpreting our Heritage. Chapel Hill, NC: University of North Carolina Press, 2007.

Timothy, Dallen J. Cultural Heritage and Tourism. Bristol: Channel View Publications, 2011.

Walsh, Kevin. The Representation of the Past: Museums and Heritage in the Post-Modern World. London and New York: Routledge, 1992.

Warren, Julie A N and C Nicholas Taylor. Developing Heritage Tourism in New Zealand. Wellington: Centre for Research, Evaluation and Social Assessment Ltd, 2001. 